\title{
Next generation sequencing and comparative analyses of Xenopus mitogenomes
}

Rhiannon E Lloyd ${ }^{1,3 *}$, Peter G Foster ${ }^{2}$, Matthew Guille ${ }^{1}$ and D Timothy J Littlewood ${ }^{2}$

\begin{abstract}
Background: Mitochondrial genomes comprise a small but critical component of the total DNA in eukaryotic organisms. They encode several key proteins for the cell's major energy producing apparatus, the mitochondrial respiratory chain. Additonally, their nucleotide and amino acid sequences are of great utility as markers for systematics, molecular ecology and forensics. Their characterization through nucleotide sequencing is a fundamental starting point in mitogenomics. Methods to amplify complete mitochondrial genomes rapidly and efficiently from microgram quantities of tissue of single individuals are, however, not always available. Here we validate two approaches, which combine long-PCR with Roche 454 pyrosequencing technology, to obtain two complete mitochondrial genomes from individual amphibian species.
\end{abstract}

Results: We obtained two new xenopus frogs (Xenopus borealis and $X$. victorianus) complete mitochondrial genome sequences by means of long-PCR followed by 454 of individual genomes (approach 1) or of multiple pooled genomes (approach 2), the mean depth of coverage per nucleotide was 9823 and 186, respectively. We also characterised and compared the new mitogenomes against their sister taxa; X. laevis and Silurana tropicalis, two of the most intensely studied amphibians. Our results demonstrate how our approaches can be used to obtain complete amphibian mitogenomes with depths of coverage that far surpass traditional primer-walking strategies, at either the same cost or less. Our results also demonstrate: that the size, gene content and order are the same among xenopus mitogenomes and that $S$. tropicalis form a separate clade to the other xenopus, among which $X$. laevis and $X$. victorianus were most closely related. Nucleotide and amino acid diversity was found to vary across the xenopus mitogenomes, with the greatest diversity observed in the Complex 1 gene nad4l and the least diversity observed in Complex 4 genes (cox1-3). All protein-coding genes were shown to be under strong negative (purifying selection), with genes under the strongest pressure (Complex 4) also being the most highly expressed, highlighting their potentially crucial functions in the mitochondrial respiratory chain.

Conclusions: Next generation sequencing of long-PCR amplicons using single taxon or multi-taxon approaches enabled two new species of Xenopus mtDNA to be fully characterized. We anticipate our complete mitochondrial genome amplification methods to be applicable to other amphibians, helpful for identifying the most appropriate markers for differentiating species, populations and resolving phylogenies, a pressing need since amphibians are undergoing drastic global decline. Our mtDNAs also provide templates for conserved primer design and the assembly of RNA and DNA reads following high throughput "omic" techniques such as RNA- and ChIP-seq. These could help us better understand how processes such mitochondrial replication and gene expression influence xenopus growth and development, as well as how they evolved and are regulated.

Keywords: Xenopus, Mitochondrial DNA, Next generation sequencing, Phylogeny, Mitogenomics, Comparative analyses, Variation, Selection and molecular markers

\footnotetext{
* Correspondence: rhiannon.lloyd@port.ac.uk

1 Institute of Biomedical and Biomolecular Sciences, University of Portsmouth,

Portsmouth PO1 2DT, UK

${ }^{3}$ Institute of Zoology, Zoological Society of London, Regent's Park, London, NW1 4RY, UK

Full list of author information is available at the end of the article
}

\section{() Biomed Central}

(c) 2012 Lloyd et al.; licensee BioMed Central Ltd. This is an Open Access article distributed under the terms of the Creative Commons Attribution License (http://creativecommons.org/licenses/by/2.0), which permits unrestricted use, distribution, and reproduction in any medium, provided the original work is properly cited. 


\section{Background}

Metazoan cells are formed from a combination of nuclear (chromosomal) DNA and mitochondrial (extrachromosomal) DNA (mtDNA). Animal mitochondrial genomes commonly include two ribosomal rRNAs, 22 tRNAs and 13 protein-coding genes. The latter geneclass encode for the proteins of the respiratory chain (RC), a multi-complex system (I to V), which in aerobic cells, transports electrons from NADH or $\mathrm{FADH}_{2}$ to molecular oxygen. This results in a proton gradient across the inner mitochondrial membrane that drives the synthesis of cellular energy (ATP). Mutations in mitochondrial genes and some of the 80 or so nuclear genes that make up the RC are associated with a broad range of diseases, ageing and cancer [1].

Mitochondrial genomes are of intrinsic importance for cellular function, but through their nucleotide and amino acid sequences are also of great utility as a source of markers for systematics and molecular ecology (e.g., [2]), and also in forensics (e.g., [3,4]). As their characterization is becoming easier and cheaper, increasing interest in comparative mitogenomics and the use of entire mtDNAs in systematics is gathering pace for some animal groups, particularly vertebrates; e.g. birds [5], mammals [6], fish [7] and amphibians. Currently, there are over 94 complete mtDNAs characterized for Amphibia (e.g. [8-11]), and many more for the other groups.

Amphibians colonized land $\sim 350$ million years ago and have since evolved into a wide variety of ecological and morphological types. Over 6,300 species of amphibians have been described to date, with the number of new species being discovered increasing annually [12]. Paradoxically, amphibian populations are undergoing a drastic global decline due to anthropogenic influences such as habitat destruction and pollution but also due to diseases such as the fungus Batrachochytrium dendrobatidis (e.g. see [13]). Thus, there is a pressing need to catalogue and monitor an ever-changing amphibian biodiversity, and to record fluctuations in species ranges as they are influenced by disease, environmental and ecological change. Many amphibian species can be morphologically similar over the course of their life cycles but molecular tools can aid in their identification, regardless of developmental stage. Typically, a relatively small sequence of mtDNA (a 'DNA barcode') encompassing part of one gene (e.g. $r r n L$; [14]) or a few genes (e.g. cytb, $r r n S$ and $r r n L$; [15]) is used for resolving the identity and/or the phylogeny of amphibian species. DNA barcode efficacy depends upon a marker being able to differentiate between inter- and intra-specific variation and they are not always completely reliable [16]. Nucleotide diversity across the mitochondrial genomes of Metazoa is also highly variable [17], suggesting that molecularbased studies might benefit from the study of complete
mtDNAs. Depending on goals and methodology, complete mtDNAs provide access to regions of high variation (useful for differentiating taxa, population genetics identifying individuals or species specific primer design), low variation (useful for universal primer design, alignment and resolving deeper phylogenies), or simply an opportunity to select from among all available sites to devise markers for a particular analysis or purpose (e.g. [18]).

Traditional approaches for sequencing them have required grams of tissue to extract and enrich sufficient quantities of 'pure' mtDNA (e.g. [19]). For small-bodied amphibians, this might necessitate the pooling of tissues from several individuals, increasing the chance of heterogeneous mtDNA variants. Also, trace amounts of nuclear DNA (nDNA) may remain in the 'pure' mtDNA, thus introducing the possibility of amplifying mitochondrial pseudogenes and introducing errors into the final sequence (see [20]). Enrichment for mitochondrial DNA can minimize the likelihood of amplifying mitochondrial pseudogenes [21], and targeted long-PCR based approaches are likely to avoid single, or short concatenated lengths of pseudogenes. Even if pure mtDNA is obtained, unless a suitable optimized primer set for the target species is available, primer-walking (the most common method used to obtain complete mitochondrial genomes to date) is time-consuming.

In this study we validate two similar approaches for rapidly and efficiently obtaining complete mitochondrial genomes from individual amphibian species. Starting with as little as one egg, both approaches combine longPCR with next generation sequencing (Roche 454 pyrosequencing technology). Amplifying complete mtDNAs in a few overlapping fragments using long-PCR reduces the amount of starting material; we achieved complete coverage of mtDNAs with just two primer pairs. Our first approach is more costly and involves long-PCR followed by 454 sequencing of individual mtDNAs and generates high quality sequence data, with a very high depth of coverage per nucleotide (up to 6000x; [22]). This amount of coverage is unnecessarily high for most applications, thus a second approach that involves longPCR followed by 454 of multiple pooled mtDNAs was also validated [23], offering a better balance between cost and data quality. The depth of coverage per nucleotide obtained using the latter approach still far exceeds that commonly obtained by primer-walking (typically by $>15 \times$; [23]).

We chose to validate the two approaches for amphibians in general using material from Xenopus, in part due to ease of access to material but also due to their popularity as a model organism for understanding vertebrate growth and development (reviewed in [24]). Here we use the term 'xenopus' as a common noun for frogs 
in the genera Xenopus and Silurana, sister taxa that were until recently combined in a single genus. Two new complete Xenopus mitochondrial genomes were obtained; Xenopus borealis and X. victorianus. The latter represents the first mitochondrial genome obtained from the next generation sequencing of so many $(>450)$ pooled long-PCR amplicons. Two existing xenopus sequences ( $X$. laevis and Silurana tropicalis) were used to design the 'universal' primers for the long-PCR and to annotate the features of the new genomes, and used as a basis for comparative analyses. Although xenopus are the most intensively studied amphibians, providing insights into cellular reprogramming, organogenesis, regeneration, gene regulatory networks and protein interactions [24], the role of mitochondrial DNA (mtDNA) in these processes has received relatively little attention. Characterizing mtDNAs of individual species and conducting comparative mitogenomic analyses are important first steps in developing this knowledge further. We analysed xenopus mtDNAs in terms of simple descriptors and pairwise comparisons involving measures of variation and selection to explore further the utility of mitochondrial genomes in xenopus research. Species of Xenopus are also all notably polyploid, which renders nuclear gene markers less suitable for reconstructing phylogenies. In this context we assessed the suitability of complete mitochondrial genomes alone in resolving xenopus phylogeny, as well as the suitability of existing mtDNA barcodes for differentiating xenopus species, populations and individuals.

\section{Results and discussion}

Verification of long-PCR amplicon identity and primer region sequences

The complete mitochondrial genome of one female each of $X$. borealis $(\mathrm{XB})$ and $X$. victorianus $(\mathrm{XV})$ was obtained by long-PCR amplification of $10 \mathrm{ng}$ of egg DNA in two adjacent amplicons. Amplicon 1 was $\sim 8,000$ bp and amplicon 2 was $\sim 9,500$ bp in size, as predicted from published mtDNAs of xenopus frogs (Figure 1). Typically, each long-PCR reaction yielded $5 \mu \mathrm{g}$ of each amplicon, as determined via the Picogreen assay. Conventional PCR amplification of amplicon 1 with $r r n L$ and/or cox 1 primers generated $\sim 580 \mathrm{bp}$ and $190 \mathrm{bp}$ fragments, respectively (Figure 1). The sequence obtained from the $r r n L$ fragment was $100 \%$ identical to that deposited in the NCBI nucleotide database for Xenopus borealis, confirming the specific identity of the $\mathrm{XB}$ sample used in this study. Sequences of $\operatorname{cox} 1$ for $\mathrm{XB}$ are absent from the database. Nonetheless, the sequence obtained using the cox 1 primers was $80 \%$ and $81 \%$ identical to corresponding regions found within the $X$. laevis (XL) and Silurana tropicalis (ST) mitochondrial genomes. Reference sequences for $r r n L$ of XV were also absent from the database, but the sequence obtained shared a $98 \%$ nucleotide identity with the corresponding region in the XL mitochondrial genome. Since the two long-PCR amplicons were adjacent, rather than overlapping, fragments (294bp and 912bp) containing the LongF1/R1 and Long F2/R2 primer regions, respectively, were amplified (Figure 1) and sequenced. Each primer region was

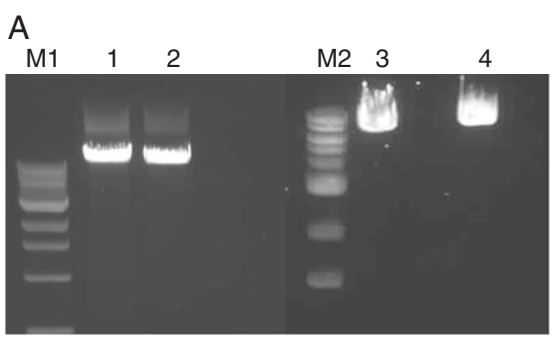

B
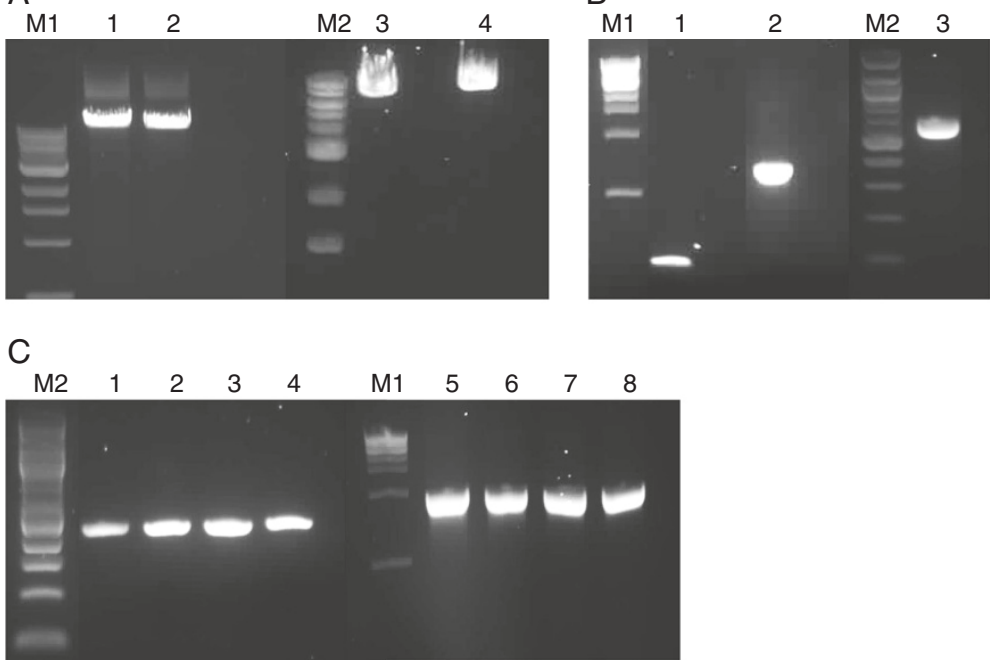

Figure 1 Long PCR, COX1, 16S, primer region 1 and primer region 2 amplicons. Agarose gel electrophoresis of (A) Xenopus borealis (XB; lanes 1 and 2) and X. victorianus (XV; lanes 3 and 4) PCR fragments using Long F1/R2 (lanes 1 and 3) and Long F2/R1 primers (lanes 2 and 4). (B) XB (lanes 1 and 2) and XV (lane 3) PCR fragments using COX1 (lane 1) and 16SA-Lmod/H (lanes 2 and 3) primers. (C) XB (lanes 1-2 and 5-6) and XV (lanes 3-4 and 7-8) PCR fragments using AMP1F/R (lanes 1-4) and AMP2F/R (lanes 5-8) primers. M1 and M2 = $1 \mathrm{~kb}$ and 100bp DNA ladders, respectively. 
$100 \%$ identical to the corresponding regions found within the appropriate Xenopus mitochondrial genome derived by 454 (this study).

\section{Automated sequencing and assembly of the Xenopus mitochondrial genomes}

The complete mitochondrial genome sequences of Xenopus borealis (XB; GenBank accession no. JX155859) and $X$. victorianus (XV; GenBank accession no. JX155858) were 17,474 and 17,716 bp in size, respectively (Tables 1 and 2, Figure 2), thus similar in size to the two published Xenopus sequences (XL and ST: 17,552 and $17,619 \mathrm{bp}$, respectively). The XB and XV mitochondrial genomes were assembled from 499,995 and 9,864 reads respectively; see Table 1 . The mean read lengths were $\sim 535$ (XB) and $~ 862$ (XV) nucleotides and the total data contributing to the assembled sequences was $171.6 \mathrm{Mb}(\mathrm{XB})$ and $7.6 \mathrm{Mb}(\mathrm{XV})$ (Table 1). Mean depth of coverage (DOC) for every nucleotide position ranged from 4923-32030 (XB) and 1-643 (XV) (Table 1), and the mean DOC over the entire mitochondrial genome was $\sim 9823(\mathrm{XB})$ and $\sim 186(\mathrm{XV})$.

\section{Annotation and characterisation of the Xenopus mitochondrial genomes \\ Length, gene content and order}

Table 2 compares the full mitogenomes of the four xenopus species, indicating considerable conservation in gene content, size and arrangement. The small differences in size between the xenopus mitochondrial genomes ( $250 \mathrm{bp}$ ) largely relates to an expansion of the D-loop, which is $1909 \mathrm{bp}$ in $\mathrm{XB},+225 \mathrm{bp}$ in $\mathrm{XL},+135 \mathrm{bp}$ in ST and +244 bp in XV.

The gene content and order is the same for all four xenopus mitochondrial genomes in having 13 protein coding genes (the cytochrome c oxidase subunits 1-3 ( $\operatorname{cox} 1-\cos 3)$, the nicotinamide dehydrogenase subunits 1-6 (nad1-nad6 and nad4L), cytochrome b (cytb) and adenosine triphosphatase subunits 6 and 8 (atp6 and atp8), 22 transfer RNAs (tRNAs) and the small ( $r r n S$ ) and large $(r r n L)$ ribosomal RNAs (Table 2 and Figure 2). All protein coding genes, apart from nad6, are predicted to be transcribed from the same strand and in the same direction.
Since the gene order and content of mitochondrial genomes is thought to be reflective of phylogenetic relationships, with such features changing relatively rarely between closely related taxa [8], it is not surprising they are identical for the four xenopus mitochondrial genomes. The gene order and content of the four xenopus mitochondrial genomes is also typical of that found in vertebrates (e.g. human, bovine and mouse; [25]), as is often the case for "Archaeobatrachian" (primitive) anurans like xenopus $[8,10,25]$ but not "Neobatrachian" (more derived) anurans [19].

In higher eukaryotes, the H-strand and L-strands each contain a distinct replication origin (OH and $\mathrm{OL})$. Hstrand replication begins in the D-loop, whereas Lstrand replication does not begin until approximately two-thirds of the $\mathrm{H}$-strand has been replicated. The ST, $\mathrm{XB}$ and XV D-loops each contained a sequence 75-90\% similar to the XL OH sequence (nt 16980-17021). Similarly, the ST, XB and XV mitochondrial genomes each contained a sequence $79-91 \%$ similar to the OL sequence (nt 5092-5128). These regions likely represent the replication origins in these species.

\section{Base-pair composition, codon usage and amino acid propensity}

The mean GC content for all xenopus $\mathrm{H}$-strand proteincoding genes was similar $(39.3 \% \pm 3.6)$, as was the asymmetric usage of the four base pairs between the $\mathrm{H}$ - and L-strands, i.e. the GC skew is -0.32 ( $\mathrm{G}$ is preferentially located on the L-strand) and the AT skew is -0.02 (with more A in L-strand); see Table 3. Like other Chordata, xenopus $\mathrm{H}$-strand protein coding genes are relatively GC-rich when compared to the following groups e.g. Annelida, Arthropoda, Cnidaria, Echinodermata, Mollusca, Platyhelminthes and Porifera that all have lower GC-means (range $23.64 \%$ to $38.18 \%$ ). Surprisingly, Xenopus $\mathrm{H}$-strand protein coding gene GCrichness in this study is most similar to that reported for Mammalia and Testudines (40.13 and 38.83, respectively) rather than that reported for Amphibia (37.45), previously. Calculating GC and AT skew indices [26] revealed that xenopus H-strand protein coding genes show an asymmetric distribution of the four bases between the $\mathrm{H}$ and L-strands, like many other metazoans [27]. Unusual among Metazoa, the GC and AT asymmetries observed in

Table 1 Consensus sequence length and read statistics for the Xenopus borealis and $X$. victorianus mitochondrial genomes obtained using 454

\begin{tabular}{|c|c|c|c|c|c|c|c|c|}
\hline Species & $\begin{array}{c}\text { Total sequence } \\
\text { length (nt) }\end{array}$ & $\begin{array}{l}\text { Read } \\
\text { output }\end{array}$ & $\begin{array}{c}\text { Reads } \\
\text { mapped (\%) }\end{array}$ & $\begin{array}{c}\text { Total sequence } \\
\text { output (nt) }\end{array}$ & $\begin{array}{l}\text { Total sequence } \\
\text { mapped (\%) }\end{array}$ & $\begin{array}{c}\text { Read } \\
\text { length (nt) }\end{array}$ & $\begin{array}{l}\text { Mean read } \\
\text { length (SD) }\end{array}$ & $\begin{array}{c}\text { DOC/ } \\
\text { nt }\end{array}$ \\
\hline X. borealis & 17474 & 499995 & $\begin{array}{c}489725 \\
(97.95 \%)\end{array}$ & 172077728 & 171646577 (99.75\%) & $57-1201$ & 535.79 (111.3) & $\begin{array}{l}4923- \\
32030\end{array}$ \\
\hline X. victorianus & 17716 & 9864 & $6627(67.18 \%)$ & 8500481 & 3432828 (40.40\%) & $324-1401$ & 861.77 (196.86) & $1-643$ \\
\hline
\end{tabular}

Abbreviations: Nt: nucleotide. SD: standard deviation. \%: percentage. DOC: depth of coverage. 
Table 2 Length and position of genes in the mitochondrial genomes of Xenopus

\begin{tabular}{|c|c|c|c|c|c|c|c|c|c|c|c|c|c|c|c|c|c|}
\hline \multirow{3}{*}{$\begin{array}{l}\text { Feature } \\
\text { tRNA }\end{array}$} & \multirow{3}{*}{$\begin{array}{c}\text { Description } \\
\text { Phe }\end{array}$} & \multicolumn{8}{|c|}{ Xenopus laevis } & \multicolumn{8}{|c|}{ Silurana $(X$.$) tropicalis$} \\
\hline & & \multicolumn{2}{|c|}{$\begin{array}{c}\text { Position } \\
\text { (nt) }\end{array}$} & \multirow{2}{*}{$\begin{array}{c}\begin{array}{c}\text { Length } \\
\text { (nt) }\end{array} \\
69\end{array}$} & \multirow[t]{2}{*}{$\begin{array}{l}\text { Start/ } \\
\text { Stop }\end{array}$} & \multirow{2}{*}{\begin{tabular}{|c|}
$\begin{array}{c}A \\
(\%)\end{array}$ \\
33.3 \\
\end{tabular}} & \multirow{2}{*}{$\begin{array}{c}\begin{array}{c}\text { C } \\
(\%)\end{array} \\
23.2 \\
\end{array}$} & \multirow{2}{*}{$\begin{array}{c}\begin{array}{c}\mathbf{G} \\
(\%)\end{array} \\
24.6\end{array}$} & \multirow{2}{*}{$\begin{array}{c}\begin{array}{c}\mathbf{T} \\
\text { (\%) }\end{array} \\
18.9\end{array}$} & \multicolumn{2}{|c|}{$\begin{array}{l}\text { Position } \\
\text { (nt) }\end{array}$} & \multirow{2}{*}{$\begin{array}{c}\begin{array}{c}\text { Length } \\
\text { (nt) }\end{array} \\
68\end{array}$} & \multirow[t]{2}{*}{$\begin{array}{l}\text { Start/ } \\
\text { Stop }\end{array}$} & \multirow{2}{*}{\begin{tabular}{|c|}
$\begin{array}{c}A \\
(\%)\end{array}$ \\
38.2 \\
\end{tabular}} & \multirow{2}{*}{\begin{tabular}{c|}
$\begin{array}{c}C \\
(\%)\end{array}$ \\
22.1 \\
\end{tabular}} & \multirow{2}{*}{\begin{tabular}{c|}
$\mathbf{G}$ \\
$(\%)$ \\
22.1
\end{tabular}} & \multirow{2}{*}{$\begin{array}{c}\begin{array}{c}\mathbf{T} \\
\text { (\%) }\end{array} \\
17.6\end{array}$} \\
\hline & & 1 & 69 & & & & & & & 1 & 68 & & & & & & \\
\hline rRNA & $r r n S$ & 70 & 888 & 819 & & 32.5 & 25.5 & 19.9 & 22.1 & 69 & 1011 & 943 & & 32.7 & 27.8 & 20.0 & 19.5 \\
\hline tRNA & Val & 889 & 957 & 69 & & 34.8 & 24.6 & 13.0 & 27.6 & 1012 & 1081 & 70 & & 32.9 & 28.6 & 14.3 & 24.2 \\
\hline rRNA & $\mathrm{rrnL}$ & 958 & 2588 & 1631 & & 36.4 & 21.0 & 17.7 & 24.9 & 1082 & 2716 & 1635 & & 34.9 & 24.1 & 18.5 & 22.5 \\
\hline tRNA & Lee (UUR) & 2589 & 2663 & 75 & & 24.0 & 26.7 & 24.0 & 25.3 & 2717 & 2791 & 75 & & 25.3 & 25.3 & 22.7 & 26.7 \\
\hline Gene & nad1 & 2664 & 3635 & 972 & ATG/TAG & 31.6 & 24.9 & 12.3 & 31.2 & 2792 & 3759 & 968 & ATG/TAG & 28.0 & 30.0 & 13.7 & 28.3 \\
\hline tRNA & lle & 3635 & 3705 & 71 & & 31.0 & 21.1 & 22.5 & 25.4 & 3760 & 3830 & 71 & & 28.2 & 23.9 & 25.4 & 22.5 \\
\hline tRNA & $\mathrm{Gln}[\mathrm{C}]$ & 3705 & 3775 & 71 & & 21.1 & 14.1 & 31.0 & 33.8 & 3830 & 3900 & 71 & & 21.1 & 14.1 & 31.0 & 33.8 \\
\hline tRNA & Met & 3775 & 3843 & 69 & & 31.9 & 26.1 & 14.5 & 27.5 & 3900 & 3968 & 69 & & 31.9 & 24.6 & 14.5 & 29.0 \\
\hline Gene & nad2 & 3844 & 4881 & 1038 & ATG/TAG & 31.8 & 26.9 & 10.2 & 31.1 & 3969 & 5004 & 1036 & ATG/TAG & 29.5 & 33.3 & 9.7 & 27.5 \\
\hline tRNA & Trp & 4880 & 4948 & 69 & & 36.2 & 28.3 & 18.8 & 16.7 & 5005 & 5073 & 69 & & 33.3 & 23.2 & 23.2 & 20.3 \\
\hline tRNA & Ala [C] & 4951 & 5019 & 69 & & 30.4 & 13.0 & 20.3 & 36.3 & 5077 & 5145 & 69 & & 29.0 & 13.0 & 21.7 & 36.3 \\
\hline tRNA & Asn $[C]$ & 5021 & 5091 & 71 & & 23.9 & 15.5 & 28.2 & 32.4 & 5147 & 5219 & 73 & & 24.7 & 17.8 & 26.0 & 31.5 \\
\hline tRNA & Cys [C] & 5190 & 5259 & 70 & & 25.8 & 22.7 & 28.8 & 22.7 & 5258 & 5323 & 66 & & 25.8 & 22.7 & 31.8 & 19.7 \\
\hline tRNA & Tyr [C] & 6817 & 6887 & 71 & & 21.4 & 20.0 & 31.4 & 27.2 & 5324 & 5393 & 70 & & 20.0 & 22.9 & 31.4 & 25.7 \\
\hline Gene & $\operatorname{cox} 1$ & 5262 & 6816 & 1555 & ATG/AAT & 28.6 & 22.4 & 16.5 & 32.5 & 5395 & 6951 & 1557 & GTG/TAA & 27.3 & 25.1 & 17.5 & 30.1 \\
\hline tRNA & Ser (UCN) [C] & 6817 & 6887 & 71 & & 26.8 & 16.9 & 28.2 & 28.1 & 6954 & 7024 & 71 & & 25.4 & 15.5 & 28.2 & $\overline{30.9}$ \\
\hline tRNA & Asp & 6903 & 6971 & 69 & & 31.9 & 21.7 & 23.2 & 23.2 & 7040 & 7108 & 69 & & 37.3 & 26.1 & 18.8 & 17.8 \\
\hline Gene & $\cos 2$ & 6974 & 7661 & 688 & $\mathrm{ATG} / \mathrm{T}$ & 32.1 & 24.4 & 14.7 & 28.8 & 7111 & 7798 & 688 & $\mathrm{ATG} / \mathrm{T}$ & 31.4 & 28.2 & 15.1 & 25.3 \\
\hline
\end{tabular}


Table 2 Length and position of genes in the mitochondrial genomes of Xenopus (Continued)

\begin{tabular}{|c|c|c|c|c|c|c|c|c|c|c|c|c|c|c|c|c|c|}
\hline \multirow{3}{*}{$\begin{array}{l}\text { Feature } \\
\text { tRNA }\end{array}$} & \multirow{3}{*}{$\begin{array}{c}\text { Description } \\
\text { Lys }\end{array}$} & \multicolumn{8}{|c|}{ Xenopus laevis } & \multicolumn{8}{|c|}{ Silurana $(X$.$) tropicalis$} \\
\hline & & \multicolumn{2}{|c|}{$\begin{array}{l}\text { Position } \\
\text { (nt) }\end{array}$} & \multirow{2}{*}{$\begin{array}{c}\begin{array}{c}\text { Length } \\
\text { (nt) }\end{array} \\
75\end{array}$} & \multirow[t]{2}{*}{$\begin{array}{l}\text { Start/ } \\
\text { Stop }\end{array}$} & \multirow{2}{*}{$\begin{array}{c}\begin{array}{c}A \\
(\%)\end{array} \\
32.0\end{array}$} & \multirow{2}{*}{$\begin{array}{l}\begin{array}{c}\text { C } \\
(\%)\end{array} \\
24.0\end{array}$} & \multirow{2}{*}{\begin{tabular}{|c|}
$\begin{array}{c}\text { G } \\
(\%)\end{array}$ \\
20.0
\end{tabular}} & \multirow{2}{*}{$\begin{array}{c}\begin{array}{c}\mathbf{T} \\
(\%)\end{array} \\
24.0\end{array}$} & \multicolumn{2}{|c|}{$\begin{array}{l}\text { Position } \\
\text { (nt) }\end{array}$} & \multirow{2}{*}{$\begin{array}{c}\text { Length } \\
\text { (nt) }\end{array}$} & \multirow[t]{2}{*}{$\begin{array}{l}\text { Start/ } \\
\text { Stop }\end{array}$} & \multirow{2}{*}{$\begin{array}{c}\begin{array}{c}A \\
(\%)\end{array} \\
31.1\end{array}$} & \multirow{2}{*}{$\begin{array}{c}\begin{array}{c}\mathrm{C} \\
(\%)\end{array} \\
28.4\end{array}$} & \multirow{2}{*}{\begin{tabular}{|c|}
$\begin{array}{c}\text { G } \\
(\%)\end{array}$ \\
21.6
\end{tabular}} & \multirow{2}{*}{$\begin{array}{c}\begin{array}{c}\mathbf{T} \\
(\%)\end{array} \\
18.9\end{array}$} \\
\hline & & 7662 & 7736 & & & & & & & 7799 & 7872 & & & & & & \\
\hline Gene & atp8 & 7738 & 7905 & 168 & ATG/TAA & 38.1 & 28.0 & 8.3 & 25.6 & 7874 & 8041 & 168 & ATG/TAA & 37.5 & 29.2 & 9.5 & 23.8 \\
\hline Gene & atp6 & 7896 & 8576 & 681 & ATG/TAA & 30.2 & 25.4 & 10.4 & 34.0 & 8032 & 8714 & 683 & ATG/TAA & 25.3 & 33.2 & 11.4 & 30.1 \\
\hline Gene & $\operatorname{cox} 3$ & 8576 & 9356 & 781 & $\mathrm{ATG} / \mathrm{T}$ & 29.8 & 24.2 & 15.7 & 30.3 & 8715 & 9498 & 784 & $\mathrm{ATG} / \mathrm{T}$ & 26.5 & 30.2 & 16.2 & 27.1 \\
\hline tRNA & Gly & 9357 & 9426 & 70 & & 27.1 & 18.6 & 14.3 & 40.0 & 9499 & 9568 & 70 & & 38.6 & 21.4 & 14.3 & 25.7 \\
\hline Gene & nad3 & 9427 & 9769 & 343 & ATG/TAA & 26.2 & 26.2 & 13.7 & 33.9 & 9569 & 9911 & 343 & ATG/AAT & 24.8 & 30.6 & 14.3 & 30.3 \\
\hline tRNA & Arg & 9770 & 9838 & 69 & & 34.8 & 18.4 & 15.9 & 30.9 & 9912 & 9980 & 69 & & 33.3 & 24.6 & 17.4 & 24.7 \\
\hline Gene & nad4L & 9839 & 10135 & 297 & ATG/TAA & 30.3 & 23.9 & 12.8 & 33.0 & 9981 & 10277 & 297 & ATG/TAA & 23.9 & 33.0 & 15.5 & 27.6 \\
\hline Gene & nad4 & 10129 & 11512 & 1384 & $\mathrm{ATG} / \mathrm{T}$ & 32.7 & 24.6 & 11.1 & 31.6 & 10271 & 11648 & 1378 & $\mathrm{ATG} / \mathrm{T}$ & 29.0 & 31.5 & 11.5 & 28.0 \\
\hline tRNA & His & 11513 & 11580 & 68 & & 35.3 & 17.6 & 16.2 & 30.9 & 11649 & 11717 & 69 & & 36.2 & 20.3 & 15.9 & 27.6 \\
\hline tRNA & Ser (AGY) & 11581 & 11645 & 65 & & 23.1 & 24.6 & 21.5 & 30.8 & 11718 & 11785 & 68 & & 23.5 & 27.9 & 25.0 & 23.6 \\
\hline tRNA & Leu (CUN) & 11646 & 11719 & 74 & & 33.8 & 20.3 & 21.6 & 24.3 & 11786 & 11858 & 73 & & 32.9 & 21.9 & 20.5 & 24.7 \\
\hline Gene & nad5 & 11720 & 13534 & 1815 & ATG/TAA & 33.2 & 23.3 & 11.5 & 32.0 & 11859 & 13676 & 1818 & ATG/TAA & 30.5 & 30.2 & 12.7 & 26.6 \\
\hline Gene & nad6 [C] & 13530 & 14042 & 513 & ATG/AGA & 19.9 & 9.4 & 28.1 & 42.6 & 13668 & 14186 & 519 & ATG/TAA & 15.2 & 10.4 & 35.1 & 39.3 \\
\hline tRNA & Glu [C] & 14043 & 14111 & 69 & & 24.6 & 14.5 & 26.1 & 34.8 & 14187 & 14255 & 69 & & 26.1 & 14.5 & 26.1 & 33.3 \\
\hline Gene & cytb & 14114 & 15253 & 1140 & ATG/TAG & 29.5 & 25.4 & 12.6 & 32.5 & 14258 & 15400 & 1143 & ATG/TAG & 27.4 & 30.4 & 14.4 & 27.8 \\
\hline tRNA & Thr & 15253 & 15322 & 70 & & 30.0 & 22.9 & 20.0 & 27.1 & 15400 & 15470 & 71 & & 26.8 & 26.8 & 22.5 & 23.9 \\
\hline tRNA & Pro [C] & 15350 & 15418 & 69 & & 21.7 & 11.6 & 38.4 & 28.3 & 15500 & 15566 & 67 & & 22.4 & 11.9 & 29.9 & 35.8 \\
\hline Cont region & D-loop & 15419 & 17552 & 2134 & & 39.3 & 17.9 & 9.4 & 33.4 & 15567 & 17610 & 2044 & & 39.0 & 20.2 & 10.7 & 30.1 \\
\hline
\end{tabular}


Table 2 Length and position of genes in the mitochondrial genomes of Xenopus (Continued)

\begin{tabular}{|c|c|c|c|c|c|c|c|c|c|c|c|c|c|c|c|c|c|}
\hline \multirow{3}{*}{$\begin{array}{l}\text { Feature } \\
\text { tRNA }\end{array}$} & \multirow{3}{*}{$\begin{array}{c}\text { Description } \\
\text { Phe }\end{array}$} & \multicolumn{8}{|c|}{$X$. borealis } & \multicolumn{8}{|c|}{$X$. victorianus } \\
\hline & & \multicolumn{2}{|c|}{ Position (nt) } & \multirow{2}{*}{$\begin{array}{c}\text { Length (nt) } \\
68\end{array}$} & \multirow[t]{2}{*}{ Start/Stop } & \multirow{2}{*}{$\begin{array}{c}\begin{array}{c}A \\
(\%)\end{array} \\
36.8 \\
\end{array}$} & \multirow{2}{*}{$\begin{array}{c}\begin{array}{c}\mathrm{C} \\
\text { (\%) }\end{array} \\
22.1\end{array}$} & \multirow{2}{*}{\begin{tabular}{|c|}
$\begin{array}{c}\text { G } \\
\text { (\%) }\end{array}$ \\
23.5 \\
\end{tabular}} & \multirow{2}{*}{$\begin{array}{c}\begin{array}{c}\mathbf{T} \\
\text { (\%) }\end{array} \\
17.6 \\
\end{array}$} & \multicolumn{2}{|c|}{$\begin{array}{l}\text { Position } \\
\text { (nt) }\end{array}$} & \multirow{2}{*}{$\begin{array}{c}\begin{array}{c}\text { Length } \\
\text { (nt) }\end{array} \\
68\end{array}$} & \multirow[t]{2}{*}{ Start/Stop } & \multirow{2}{*}{$\begin{array}{c}\begin{array}{c}A \\
\text { (\%) }\end{array} \\
36.8 \\
\end{array}$} & \multirow{2}{*}{$\begin{array}{c}\begin{array}{c}\mathrm{C} \\
(\%)\end{array} \\
22.1\end{array}$} & \multirow{2}{*}{$\begin{array}{c}\begin{array}{c}\mathbf{G} \\
(\%)\end{array} \\
23.5\end{array}$} & \multirow{2}{*}{$\begin{array}{c}\begin{array}{c}\mathbf{T} \\
(\%)\end{array} \\
17.6\end{array}$} \\
\hline & & 1 & 68 & & & & & & & 1 & 68 & & & & & & \\
\hline rRNA & $r r n S$ & 69 & 1015 & 947 & & 32.2 & 25.0 & 19.6 & 23.2 & 69 & 1016 & 948 & & 32.3 & 25.9 & 19.6 & 22.2 \\
\hline tRNA & Val & 1016 & 1085 & 70 & & 32.9 & 24.3 & 14.3 & 28.5 & 1017 & 1085 & 69 & & 33.3 & 23.2 & 14.5 & 29.0 \\
\hline rRNA & $\mathrm{rrnL}$ & 1086 & 2720 & 1635 & & 36.5 & 19.6 & 18.2 & 25.7 & 1086 & 2720 & 1635 & & 37.1 & 21.4 & 17.7 & 23.8 \\
\hline tRNA & Lee (UUR) & 2721 & 2795 & 75 & & 25.3 & 26.7 & 22.7 & 25.3 & 2722 & 2796 & 75 & & 21.3 & 29.3 & 25.3 & 24.1 \\
\hline Gene & $\operatorname{nad} 128.3$ & 2796 & 3764 & 969 & ATG/TAG & 29.1 & 21.3 & 15.3 & 34.3 & 2801 & 3769 & 969 & ATG/TAG & 30.5 & 26.5 & 12.4 & 30.6 \\
\hline tRNA & lle & 3764 & 3834 & 71 & & 31.0 & 21.1 & 22.5 & 25.4 & 3769 & 3839 & 71 & & 31.0 & 22.5 & 22.5 & 24.0 \\
\hline tRNA & $\mathrm{Gln}[\mathrm{C}]$ & 3834 & 3904 & 71 & & 21.1 & 12.7 & 31.0 & 35.2 & 3840 & 3909 & 70 & & 20.0 & 14.3 & 13.4 & 52.3 \\
\hline tRNA & Met & 3904 & 3972 & 69 & & 33.3 & 23.2 & 14.5 & 29.0 & 3909 & 3977 & 69 & & 31.9 & 26.1 & 14.5 & 27.5 \\
\hline Gene & nad2 & 3973 & 5010 & 1038 & ATG/TAG & 31.5 & 24.2 & 11.4 & 32.9 & 3978 & 5015 & 1038 & ATG/TAG & 32.2 & 27.5 & 9.3 & 31.0 \\
\hline tRNA & Trp & 5009 & 5077 & 69 & & 36.2 & 20.3 & 17.4 & 26.1 & 5014 & 5082 & 69 & & 36.2 & 21.7 & 17.4 & 24.7 \\
\hline tRNA & Ala [C] & 5084 & 5154 & 71 & & 31.0 & 11.3 & 19.7 & 38.0 & 5084 & 5154 & 71 & & 28.2 & 12.7 & 23.9 & 35.2 \\
\hline tRNA & Asn [C] & 5154 & 5228 & 75 & & 25.3 & 20.0 & 26.7 & 28.0 & 5154 & 5228 & 75 & & 24.0 & 16.0 & 30.7 & 29.3 \\
\hline tRNA & Cys [C] & 5255 & 5320 & 66 & & 24.2 & 25.8 & 28.8 & 21.2 & 5260 & 5325 & 66 & & 24.2 & 22.7 & 30.3 & 22.8 \\
\hline tRNA & Tyr [C] & 5321 & 5392 & 72 & & 23.6 & 26.4 & 27.8 & 22.2 & 5326 & 5397 & 72 & & 22.2 & 22.2 & 29.2 & 26.4 \\
\hline Gene & $\operatorname{cox} 1$ & 5392 & 6948 & 1557 & GTG/TAA & 28.1 & 21.1 & 17.3 & 33.5 & 5397 & 6953 & 1557 & GTG/TAA & 28.5 & 23.3 & 16.1 & 32.1 \\
\hline tRNA & $\operatorname{Ser}(\mathrm{UCN})[\mathrm{C}]$ & 6950 & 7020 & 71 & & 28.2 & 18.3 & 25.4 & 28.1 & 6956 & 7026 & 71 & & 28.2 & 25.4 & 16.9 & 29.5 \\
\hline tRNA & Asp & 7031 & 7099 & 69 & & 37.7 & 15.9 & 14.5 & 31.9 & 7042 & 7109 & 68 & & 38.9 & 22.1 & 19.1 & 19.9 \\
\hline Gene & $\cos 2$ & 7102 & 7789 & 688 & $\mathrm{ATG} / \mathrm{T}$ & 32.3 & 21.9 & 14.8 & 31.0 & 7112 & 7799 & 688 & $\mathrm{ATG} / \mathrm{T}$ & 32.3 & 25.0 & 14.2 & 28.5 \\
\hline
\end{tabular}


Table 2 Length and position of genes in the mitochondrial genomes of Xenopus (Continued)

\begin{tabular}{|c|c|c|c|c|c|c|c|c|c|c|c|c|c|c|c|c|c|}
\hline \multirow{3}{*}{$\begin{array}{l}\text { Feature } \\
\text { tRNA }\end{array}$} & \multirow{3}{*}{$\begin{array}{c}\text { Description } \\
\text { Lys }\end{array}$} & \multicolumn{8}{|c|}{$X$. borealis } & \multicolumn{8}{|c|}{$X$. victorianus } \\
\hline & & \multicolumn{2}{|c|}{ Position (nt) } & \multirow{2}{*}{$\begin{array}{c}\text { Length (nt) } \\
74\end{array}$} & \multirow[t]{2}{*}{ Start/Stop } & \multirow{2}{*}{$\begin{array}{c}\begin{array}{c}\text { A } \\
(\%)\end{array} \\
29.7\end{array}$} & \multirow{2}{*}{$\begin{array}{c}\begin{array}{c}\mathrm{C} \\
(\%)\end{array} \\
25.7\end{array}$} & \multirow{2}{*}{$\begin{array}{c}\begin{array}{c}\text { G } \\
(\%)\end{array} \\
23.0\end{array}$} & \multirow{2}{*}{$\begin{array}{c}\begin{array}{c}\mathbf{T} \\
\text { (\%) }\end{array} \\
21.6\end{array}$} & \multicolumn{2}{|c|}{$\begin{array}{c}\text { Position } \\
\text { (nt) }\end{array}$} & \multirow{2}{*}{$\begin{array}{c}\text { Length } \\
\text { (nt) }\end{array}$} & \multirow[t]{2}{*}{ Start/Stop } & \multirow{2}{*}{$\begin{array}{c}\begin{array}{c}A \\
(\%)\end{array} \\
29.3 \\
\end{array}$} & \multirow{2}{*}{$\begin{array}{c}\begin{array}{c}\mathrm{C} \\
(\%)\end{array} \\
22.7\end{array}$} & \multirow{2}{*}{\begin{tabular}{c|}
$\begin{array}{c}\text { G } \\
(\%)\end{array}$ \\
12.7
\end{tabular}} & \multirow{2}{*}{$\begin{array}{c}\begin{array}{c}\mathbf{T} \\
\text { (\%) }\end{array} \\
35.3\end{array}$} \\
\hline & & 7790 & 7863 & & & & & & & 7800 & 7874 & & & & & & \\
\hline Gene & atp8 & 7865 & 8032 & 168 & ATG/TAA & 37.5 & 26.2 & 8.3 & 28.0 & 7876 & 8043 & 168 & ATG/TAA & 36.9 & 28.0 & 8.3 & 26.8 \\
\hline Gene & atp6 & 8023 & 8706 & 684 & ATG/TAA & 28.8 & 24.3 & 11.5 & 35.4 & 8034 & 8717 & 684 & ATG/TAA & 29.1 & 27.0 & 10.5 & 33.4 \\
\hline Gene & $\operatorname{cox} 3$ & 8706 & 9489 & 784 & ATG/T & 26.4 & 22.8 & 17.3 & 33.5 & 8717 & 9500 & 784 & ATG/T & 28.6 & 25.8 & 15.8 & 29.8 \\
\hline tRNA & Gly & 9490 & 9559 & 70 & & 35.7 & 21.4 & 14.3 & 28.6 & 9501 & 9570 & 70 & & 35.7 & 18.6 & 15.7 & 30.0 \\
\hline Gene & nad3 & 9560 & 9902 & 343 & ATG/T & 24.5 & 22.4 & 16.9 & 36.2 & 9571 & 9913 & 343 & ATG/T & 25.1 & 28.6 & 12.8 & 33.5 \\
\hline tRNA & Arg & 9903 & 9972 & 70 & & 35.7 & 21.4 & 15.7 & 27.2 & 9914 & 9983 & 70 & & 35.7 & 18.6 & 15.7 & 30.0 \\
\hline Gene & nad4L & 9972 & 10268 & 297 & ATG/TAA & 26.6 & 24.6 & 13.8 & 35.0 & 9983 & 10279 & 297 & ATG/TAA & 26.6 & 27.3 & 13.1 & 33.0 \\
\hline Gene & nad4 & 10262 & 11639 & 1378 & ATG/T & 30.5 & 25.1 & 11.5 & 32.9 & 10273 & 11650 & 1378 & ATG/T & 31.8 & 26.1 & 11.1 & 31.0 \\
\hline tRNA & His & 11640 & 11708 & 69 & & 30.4 & 15.9 & 20.3 & 33.4 & 11651 & 11719 & 69 & & 34.8 & 17.4 & 17.4 & 30.4 \\
\hline tRNA & Ser (AGY) & 11708 & 11774 & 67 & & 22.4 & 23.9 & 23.9 & 29.8 & 11719 & 11785 & 67 & & 22.4 & 23.9 & 23.9 & 29.8 \\
\hline tRNA & Leu (CUN) & 11774 & 11847 & 74 & & 32.4 & 16.2 & 23.0 & 28.4 & 11785 & 11858 & 74 & & 32.4 & 20.3 & 21.6 & 25.7 \\
\hline Gene & nad5 & 11848 & 13665 & 1818 & ATG/TAA & 31.4 & 23.7 & 12.6 & 32.3 & 11859 & 13676 & 1818 & ATG/TAA & 32.3 & 24.4 & 11.7 & 31.6 \\
\hline Gene & nad6 [C] & 13657 & 14175 & 519 & ATG/TAA & 19.5 & 11.9 & 29.5 & 39.1 & 13668 & 14186 & 519 & ATG/TAA & 19.8 & 9.4 & 28.7 & 42.1 \\
\hline tRNA & Glu [C] & 14176 & 14245 & 70 & & 28.6 & 11.4 & 21.4 & 38.6 & 14187 & 14257 & 71 & & 23.9 & 14.1 & 25.4 & 36.6 \\
\hline Gene & cytb & 14246 & 15388 & 1143 & ATG/TAG & 27.7 & 23.3 & 14.8 & 34.2 & 14258 & 15400 & 1143 & ATG/TAG & 28.6 & 26.2 & 13.1 & 32.1 \\
\hline tRNA & Thr & 15388 & 15458 & 71 & & 26.8 & 25.4 & 21.1 & 26.7 & 15400 & 15471 & 72 & & 29.2 & 25.0 & 20.8 & 25.0 \\
\hline tRNA & Pro [C] & 15499 & 15565 & 67 & & 20.9 & 11.9 & 31.3 & 35.9 & 15497 & 15563 & 67 & & 23.9 & 10.4 & 28.4 & 37.3 \\
\hline Cont region & D-loop & 15566 & 17474 & 1909 & & 37.2 & 19.0 & 9.8 & 34.0 & 15564 & 17716 & 2153 & & 39.3 & 19.0 & 9.1 & 32.6 \\
\hline
\end{tabular}

Initiation and termination codons and base contents (\%) are also indicated. Gene transcribed in the reverse (complementary) direction are indicated with [C]. 


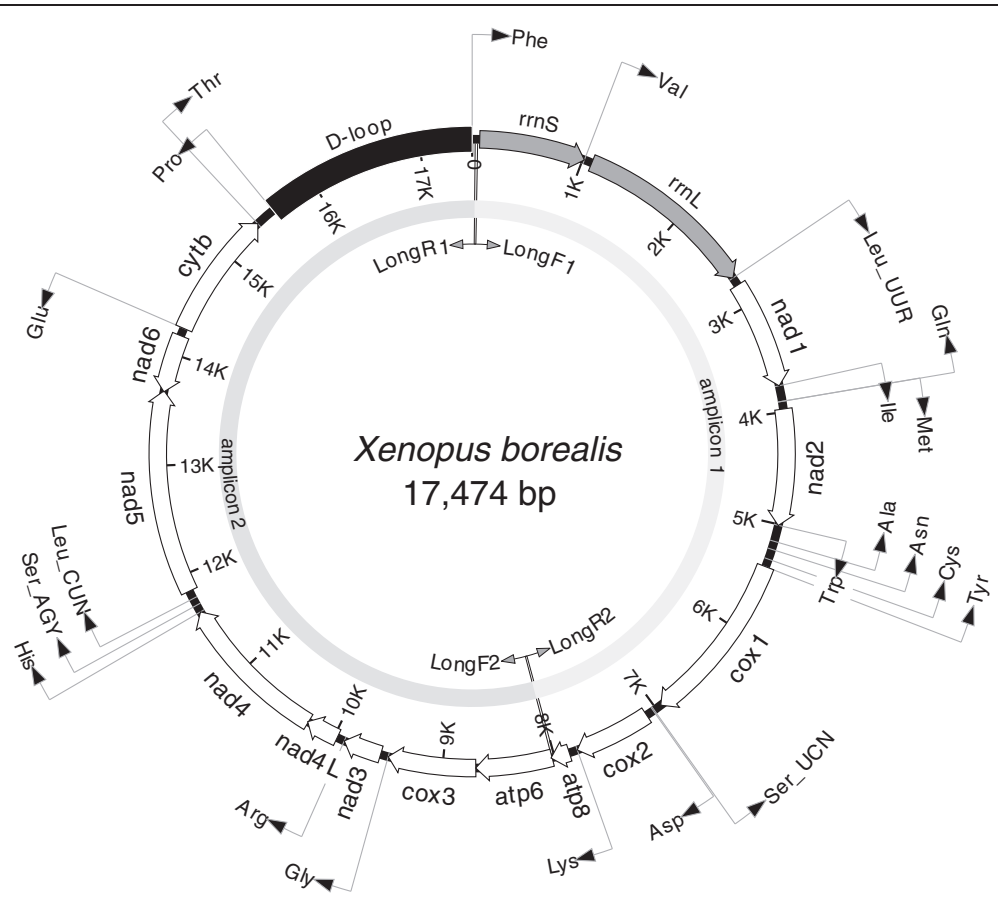

Figure 2 Xenopus borealis mitochondrial genome. The complete mitochondrial genome of Xenopus borealis (17,474 bp, drawn to scale) All 13 protein coding genes are shown as open arrows, 2 ribosomal RNAs as shaded arrows and 22 tRNAs as arrowed lines. Each tRNA is shown by its single letter amino acid code. The two leucine and two serine tRNAs are differentiated by their respective anti-codons. The direction of transcription is indicated by the arrows. Also shown is the non-coding D-loop (control region, black) and the position of the primers (LongF1/R2 and LongF2/R1) used to generate the two long-PCR amplicons, which were pooled and sequenced using 454 technology.

xenopus $\mathrm{H}$-strand protein coding genes were both negative (a negative GC-skew and a positive AT-skew is more usual). However, the GC-skew (-0.32) observed in xenopus $\mathrm{H}$-strand coding genes is more pronounced than the AT-skew (-0.02), typical among Metazoans. Such asymmetry is thought to be positively correlated with how long the $\mathrm{H}$-strand remains single stranded during replication, increasing the time it is exposed to mutation [28]. On this basis, the mutation rate in xenopus $\mathrm{H}$-strand protein coding genes could well be different to that observed in other amphibians $(-0.25 ;[27])$.

Table 3 GC and AT-skew indices

\begin{tabular}{|c|c|c|c|c|}
\hline & Mean A + T & AT & Mean $\mathrm{C}+\mathrm{G}$ & GC \\
\hline & $(\%)$ & skew & (\%) & skew \\
\hline$X \mathrm{~L}$ & 62.4 & -0.01 & 37.6 & -0.32 \\
\hline $\mathrm{ST}$ & 56.2 & 0.01 & 43.8 & -0.37 \\
\hline $\mathrm{XB}$ & 62.7 & -0.06 & 37.3 & -0.25 \\
\hline$X V$ & 61.3 & -0.02 & 38.7 & -0.35 \\
\hline ALL & 60.7 & -0.02 & 39.3 & -0.32 \\
\hline SD & 3.4 & -0.3 & 3.6 & -0.6 \\
\hline
\end{tabular}

Percentage mean \pm standard deviation (SD) base-pairs in xenopus $\mathrm{H}$-strand protein-coding genes. Skew (or "asymmetry") between base-pairs was calculated as follows: $\mathrm{GC}$ skew $=(\mathrm{G}-\mathrm{C}) / \operatorname{total}(\mathrm{GC})$ and AT skew $=(\mathrm{A}-\mathrm{T}) /$ total (AT).
The codon usage was identical to that of other vertebrate mitogenomes, including other amphibians [29]: all 13 of the xenopus protein coding genes use ATG as an initiation codon, with the exception of the $\operatorname{cox} 1$ gene in ST, XB and XV that uses either TAA or GTG. The most frequent termination codons used by xenopus mitogenomes were TAR and AGR, again characteristic of vertebrate/amphibian mitogenomes [29]. The next most frequently used termination codon was incomplete, a single nucleotide $\mathrm{T}$, where the post-transcriptional polyadenylation is thought to complete a TAA termination codon, as suggested for amphibians and humans $([29,30]$, respectively).

\section{Phylogenetic analysis}

From the published mtDNAs available on GenBank, two taxa were selected as suitable outgroups: Hymenochirus boettgeri (NC_015615) and Pipa carvalhoi (NC_015617). Both are members of the Pipinae, sister to the Xenopodinae (the Xenopus and Silurana species) and their mtDNAs were published as part of a phylogenetic study of tongueless frogs by [31]. The full alignment of protein-coding genes consisted of 3,782 amino acids, with few indels (48 gaps in total, 6 taxa), and was deemed unambiguously aligned; of the aligned sites, 2,722 (73.3\%) were identical. The resulting Bayesian 
phylogenetic analysis of concatenated protein coding genes, analysed as amino acids, is shown in Figure 3. Each node is supported unequivocally with maximal nodal support (100\% posterior probabilities). Amongst the ingroup, the Xenopodinae, Silurana (ST) was resolved as sister to a monophyletic clade of Xenopus, within which X. laevis and $X$. victorianus were resolved as sister taxa. These results are consistent with other recently published phylogenies; e.g. one that used a 2335 bp region of mitochondrial DNA (including the $r r n S$, trn $V$ and $r r n L$ genes analysed as nucleotides; [32]) and one that used $c y t b, r r n L$ and $r r n S$ and several nuclear genes as markers (e.g. recombination-activating gene 1 (RAG1)), also analysed as nucleotides [15]. The strong nodal support within the phylogeny suggests that many more species might be accommodated in an analysis of Xenopodinae (and Pipidae) using all mitochondrial protein coding genes. Currently, there are 15 species of Xenopus and 4 species of Silurana considered valid within this subfamily [32,33]. The genera are differentiated based on their chromosome complements. In Silurana chromosome numbers are multiples of 20 (1 diploid species and 3 tetraploid), in Xenopus chromosome numbers are multiples of 18, with all species polyploid (e.g. see [34]). Extant species are distributed across Africa but fossil forms from Brazil and Argentina suggest a possible Gondwanan origin of the Pipidae, and other fossils from Africa demonstrate a considerably wider historical distribution in Africa [32]. A mitogenomic approach to the systematics of Xenopodinae may provide additional insights into their evolutionary origins and patterns of radiation.

\section{Sliding window analysis}

The four complete xenopus mitochondrial genomes were aligned in their entirety, at the nucleotide level, to

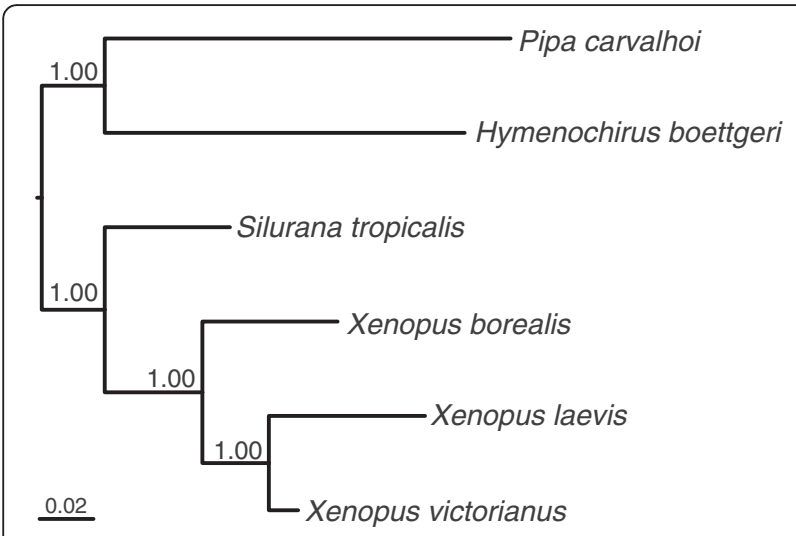

Figure 3 Phylogenetic estimates of the interrelationship of four xenopus species and two relatives based on Bayesian analysis of amino acids from concatenated protein coding sequences.

Nodal support is given by posterior probabilities; branch-length scale indicates number of substitutions per site. estimate nucleotide divergence $\mathrm{K}(\mathrm{JC})$ (average number of nucleotide substitutions per site between species with Jukes Cantor correction) across the genome as revealed by sliding window analysis using DnaSP [35]; high values of K(JC) indicate greater sequence differences. Greatest divergence was observed in the comparison between Dloops; as expected considering the considerable sequence variability and difficulty in aligning these regions. Gene by gene diversity, as estimated by nucleotide divergence, was highly variable (Figure 4), and was highest in nad4L and atp6, and least in $r r n S$. The commonly used mitochondrial 'barcodes' for amphibians, partial $r r n L$ (16S) $[14,36]$ and partial cox1 (COI) [37,38], the latter promoted by The Consortium for the Barcode of Life (www.barcodeoflife.org), are also indicated on Figure 4. Viewed in the context of overall nucleotide diversity, the 16S barcode captures less than COI, and both capture regions of relatively low sequence diversity across the mitochondrial genome. Novel molecular markers and barcodes that must achieve universality in their use across taxa, must have priming sites in conserved regions, as indicated by troughs in the graph; e.g. as seen at the 5'and 3'-ends of the 16S barcode. Given that tRNA genes can move, duplicate or change identity (e.g. [39]), ideal priming sites should be within ribosomal or protein coding genes, and as gene order changes can occur, it may be preferable to target single gene fragments.

Given the unique interest in Xenopus as a model laboratory organism, it is necessary to consider hitherto unused regions of the mtDNA that may be of use as molecular markers. Populations of Xenopus used in labs worldwide are thought to have originated from different regions of Africa, and have been interbred, and indeed inbred, to varying degrees. Different populations could be identified through their maternal lineages via mitochondrial markers. Regions of high diversity may be of greatest utility here. The taxonomy of the group is also replete with subspecies and reliable markers are required for systematic revision as well as diagnosis.

Targeting regions of Xenopus mtDNA for novel molecular marker design depends very much on the intended application, and preferred technique. PCR-based amplifications of within-gene regions for bidirectional sequencing are a common starting point for differentiating individuals, populations and species. The sliding window analysis provides some regions worthy of pursuit. Although amongst the most variable of protein-coding genes, nad4L may be too short to be usable. However, alternative genes offering reasonable length (400-1000 bp) include atp6, nad2 and nad1. By far the most variable regions of the mtDNAs is the D-loop. However, if this were to be a chosen target for within or between species study, it would likely need to be amplified in its entirety. High AT-content, the propensity for secondary structure folding and length differences 


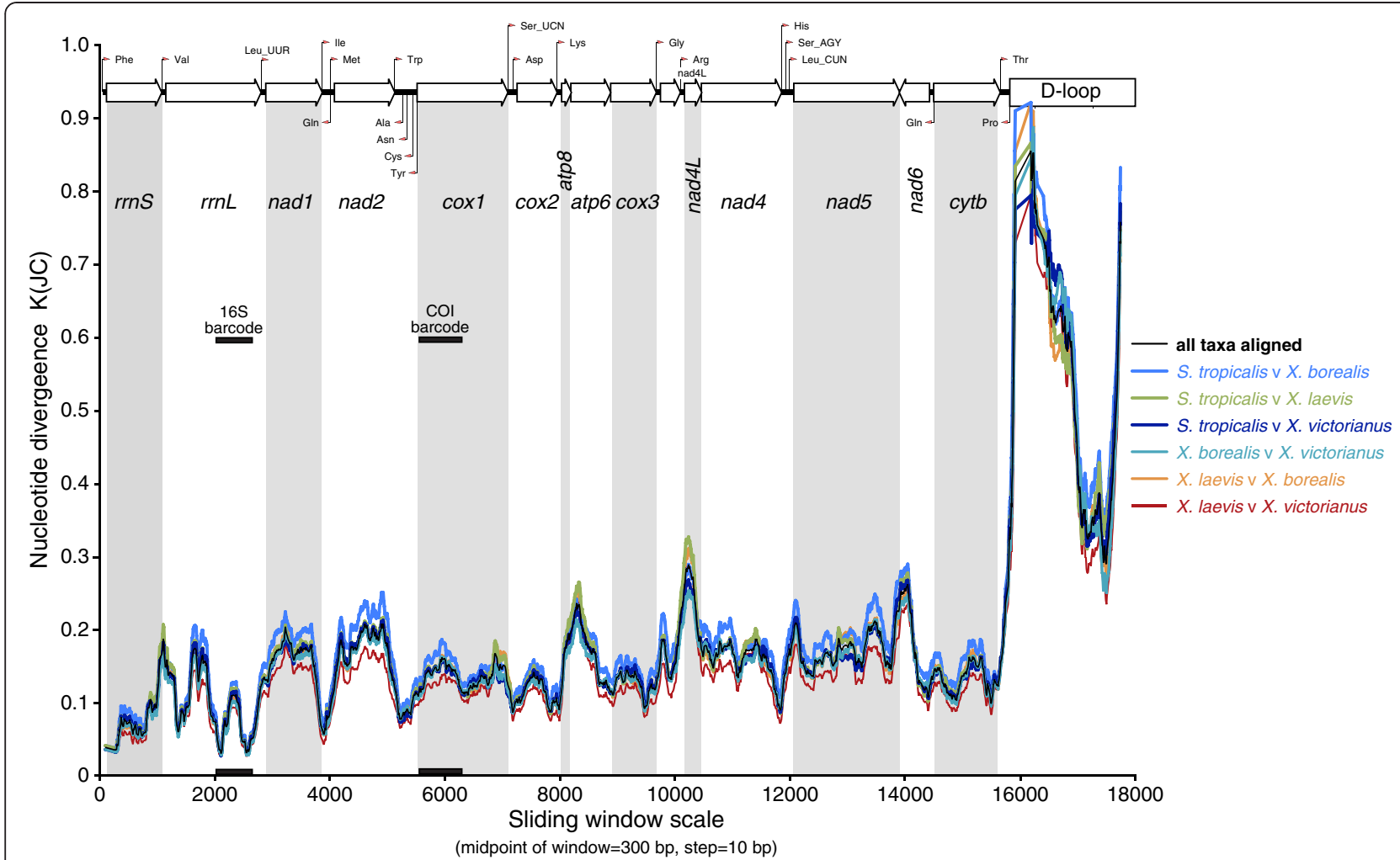

Figure 4 Sliding window analysis of complete mitochondrial genome sequences of xenopus frogs. The coloured lines show the value of nucleotide divergence $\mathrm{K}(\mathrm{JC})$ (average number of nucleotide substitutions per site between species with Jukes and Canor correction) in a sliding

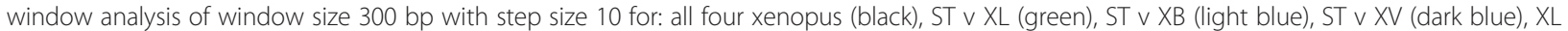
$\vee X B$ (orange), XB $\vee X V$ (turquoise) and XL and XV (red). Gene boundaries and primers and regions commonly used in DNA barcoding amphibians are indicated.

make it difficult to design suitable PCR primers within the D-loop. However, fortuitously, two well-conserved genes (cytb and rrnS) border the D-loop and these offer many regions for potential PCR primer design.

Although none of the suggested markers were tested in this study, we found the software MitoMapper (Yang et al., 2011) was readily applicable to our xenopus data, yielding either suites of primer pairs to generate overlapping amplicons for complete de novo mtDNA coverage, or primer pairs for targeting shorter gene/genome regions (data not shown). The program designs primers that will work on the input sequences as well as other closely related taxa.

Combining the two new mitogenomes with those already available will also facilitate the design of novel molecular markers for resolving e.g. the phylogenies of pipids and amphibians as a whole and the design of conserved primers for long PCR and the assembly of next generation sequencing contigs.

\section{$d N / d S$ analysis}

The ratio of nonsynonymous $(\mathrm{dN})$ to synonymous $(\mathrm{d} S)$ substitutions observed within the xenopus protein- coding sequences suggests that all genes are evolving under negative (purifying) selection. Complex IV genes (cox1-3), the Complex III gene (cyt b), some of the complex I genes (nd1, 2, 4 and 5) and one of the complex $\mathrm{v}$ genes (atp6) are under strong selection, with the remaining complex I genes (nad3, nad4L and nad6) and one of the complex V genes (atp8) under weaker selection (Figure 5). These findings are concordant with study where $\mathrm{dN} / \mathrm{dS}$ ratios were estimated from 347 complete vertebrate mitochondrial genomes, which included 54 from amphibians, that showed that purifying selection was strongest for genes that encode subunits with crucial functions in the RC [27]. Indeed, Complex IV subunits COX1-3 and Complex I subunits ND1, 2, 4 and 5 do have crucial functions in the RC. Specifically, the COX1 and COX2 subunits of Complex IV perform the electron and proton transfers, as well as creating the channels required for the dioxygen molecule to reach, and the $\mathrm{H}_{2} \mathrm{O}$ molecule to be removed from, the $\mathrm{O}_{2}$ reduction site [40]. While the COX3 subunits (Complex IV is a dimer) are also thought to be involved in proton transfers, they also provide structural stability between the COX1 and 2 subunits (reviewed in [41]). While the 


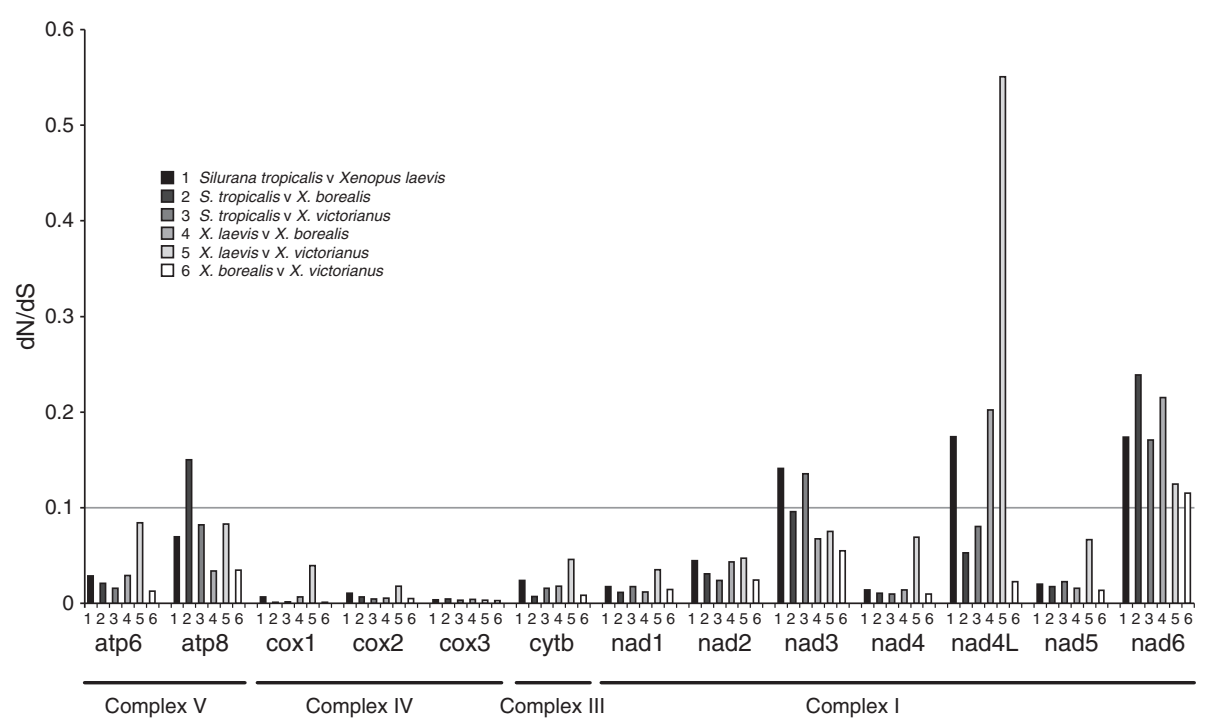

Figure 5 Ratios of nonsynonymous/synonymous (dN/dS) nucleotide substitutions between the protein-coding genes of xenopus mitochondrial genomes. Although the ratios differ considerably between genes, complexes and pairs of species, in all cases genes are evolving under negative (purifying) selective pressure $(\mathrm{dN} / \mathrm{d} S<1)$.

Complex I subunits ND5, ND4 and ND2 perform the proton pumping and ND1 provides structural stability between the membrane and peripheral domains of the complex. ND5 has an additional role as a "coupling element", connecting all the membrane subunits together [42].

\section{Expressed sequence tag analysis}

In total, 78 ESTs with $\geq 90 \%$ similarity at the nucleotide level, to the protein coding genes of ST were recovered from the cDNA libraries deposited in Xenbase [43]. Complex IV (cox1-3) genes were significantly more represented than those of Complex I (nad1-6 and nad4L) and the Complex III gene $(c y t b)(\mathrm{P}<0.003$ and $\mathrm{P}<0.05$, respectively; Figure 6). Interestingly, Complex IV genes under the strongest purifying selection were also the most highly expressed. This correlation has been observed in several organisms, from bacteria to humans (reviewed in [27]). Given that Complex IV subunits perform such crucial functions in the $\mathrm{RC}$ and are expressed so highly, it is not really surprising that the genes that encode them contain few non-synonymous substitutions, relative to other genes. Preserving Complex IV gene function by purifying selection would avoid mutations that cause amino acid changes that could lead to the production of dysfunctional subunits and ultimately, a compromised RC. This is likely to be even more important if such genes are highly expressed.

\section{NGS approaches to mtDNA sequencing}

In this study, two new Xenopus (Xenopus borealis and X. victorianus) complete mitochondrial genome sequences were obtained using a combination of long-PCR and next generation sequencing (454) of either individual or multiple pooled mtDNAs. This is the first report of amphibian mitochondrial genomes obtained using this approach. The relative ease with which the high quality genomes were obtained, due to: (1) the long-PCR step minimizing the amount of starting material (i.e. 10ng of egg total DNA) required and (2) the 454 sequencing step removing the need for an optimized primer set (necessary for a primer-walking strategy) and generating a high level of coverage (XB: 9823 and XV: 186; mean DOC),

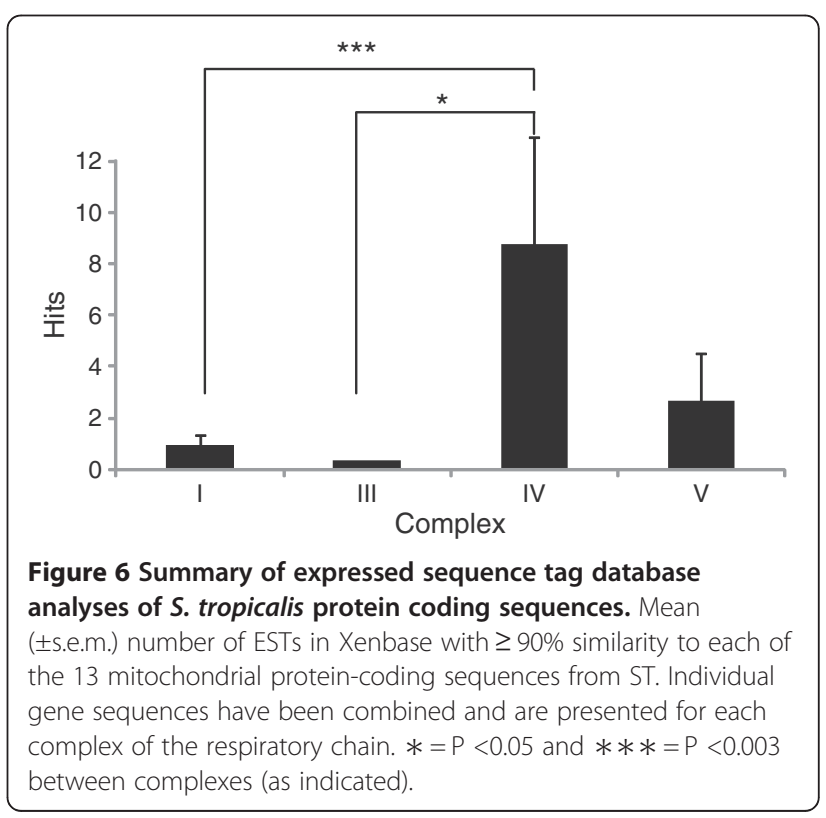


makes NGS a very promising approach for other amphibians. It is immediately applicable to other xenopus species/individuals, as all the primers used in this study were designed to be universal for xenopus mtDNAs. Furthermore, both approaches generate depths of coverage that far surpass traditional primer-walking strategies at either the same cost ( US\$1400, approach 1) or less ( US\$80, approach 2).

\section{Conclusions}

Here we provide two approaches for the rapid and efficient amplification of amphibian mitogenomes from microgram quantities of tissue. Specifically, two new xenopus mitogenomes (Xenopus borealis and X. victorianus) were obtained, characterised and compared to their sister taxa (X. laevis and Silurana tropicalis), two of the most intensely studied amphibians and popular vertebrate model organisms. We discovered the size was similar and gene content and order was the same among the xenopus and to other vertebrates. The phylogeny, generated using amino acids, was consistent with existing phylogenies for xenopus and amphibian species, however, some 15 additional species of xenopus remain to analysed using this approach and would provide additional insights into their evolution and radiation. On the one hand we reveal commonly used mitochondrial "barcodes" for differentiating amphibian species and populations fail to capture the greatest xenopus nucleotide diversity, on the other hand we provide alternative, more appropriate targets for differentiating xenopus species/populations. Our exploration of protein-coding genes in the xenopus mitogenomes reveals their function is strongly preserved by negative (purifying) selection, particularly in the case of those encoding proteins that have crucial functions in the mitochondrial respiratory chain and are highly expressed, such as the Complex IV proteins: CO1-CO3, that collectively transfer protons and electrons or confer structural stability. Our complete mitochondrial genome amplification methods and analyses are applicable to other amphibians and are therefore likely to be helpful for identifying the most appropriate markers for differentiating species, populations and resolving phylogenies, a pressing need since amphibians are undergoing drastic global decline. Our findings also provide a platform for using xenopus to better understanding the critical role mitogenomes play in complex biological problems, such as cellular reprogramming, organogenesis, regeneration, gene regulatory networks and protein interactions that control growth and development.

\section{Methods}

All reagents, materials and equipment were purchased from Sigma-Aldrich ${ }^{\circledR}$ (Gillingham, UK), unless stated otherwise.

\section{Xenopus egg collection and DNA extraction}

One adult Xenopus borealis (XB) and $X$. victorianus (XV) female was injected with a priming dose (50 U) of human chorionic gonadotropin (hCG) and, one week later, an ovulatory dose (500 U) into the dorsal lymph sac. One day after injecting the ovulatory dose, a batch of eggs was collected manually into $1 \mathrm{X}$ MBS (110 mM $\mathrm{NaCl}, 2 \mathrm{mM} \mathrm{KCl}, 1 \mathrm{mM}$ MgSO4, 2 mM NaHCO3, 0.5 $\mathrm{mM}$ Na2HPO4, $15 \mathrm{mM}$ Tris base, $\mathrm{pH}$ 7.6, acetic acid, $0.5 \mathrm{mM}$ sodium phosphate, $\mathrm{pH} 7.4$ ); dejellied using $2 \%$ $(\mathrm{w} / \mathrm{v})$ cysteine (in $1 \mathrm{X} \mathrm{MBS}$ ) and washed three times with $1 \mathrm{X}$ MBS. Groups of ten eggs (XB) or one egg (XV) were/was placed into $1.5 \mathrm{~mL}$ tubes, excess liquid removed and stored at $-70^{\circ} \mathrm{C}$. Total DNA was extracted from the eggs following thawing via: homogenisation in NETS buffer (0.3M NaCl, 1mM EDTA, $20 \mathrm{mM}$ TRIS, $\mathrm{pH}$ 7.0), mixing the homogenate in phenol:chloroform: isoamyl alcohol 25:24:1 (PCIA) and centrifugation (13,000 rpm, $15 \mathrm{~min}$ ). The aqueous layer (containing the DNA) was recovered and extracted with PCIA twice more prior to precipitating the DNA in ethanol at $-20^{\circ} \mathrm{C}$. DNA pellets were recovered from the ethanol via centrifugation (as above), air-dried and resuspended in $100 \mathrm{ul}$ of nuclease-free water by heating for $1 \mathrm{~h}$ at $65^{\circ} \mathrm{C}$.

\section{Long-PCR amplification of two mitochondrial genome regions}

The complete mitochondrial genome of each Xenopus species was amplified by long-PCR as two amplicons (1: $~ 7,961 \mathrm{bp}$, containing the $r r n L$ and cox 1 genes and 2: 9,649bp) using the Expand Long Range dNTPack kit (Roche). Each $(50 \mu \mathrm{L})$ PCR contained $10 \mathrm{ng}$ total DNA; 2 x buffer, $2.5 \mathrm{mM} \mathrm{MgCl} 2,0.5 \mu \mathrm{M}$ each dNTP, $0.3 \mu \mathrm{M}$ each of primers Long F1 and R2 (Amplicon 1) or Long F2 and R1 (Amplicon 2; Table 4 and Figure 2), 1.4\% (v/v) DMSO and $0.7 \mu \mathrm{l}$ of enzyme mix and was run on a GeneAmp ${ }^{\circledR}$ PCR system 9700 at $92^{\circ} \mathrm{C}$ for 2 min; 10 cycles at $92^{\circ} \mathrm{C}$ for $10 \mathrm{~s}, 55^{\circ} \mathrm{C}$ for $15 \mathrm{~s}, 68^{\circ} \mathrm{C}$ for $10 \mathrm{~min} ; 20$ cycles at $92^{\circ} \mathrm{C}$ for $10 \mathrm{~s}, 55^{\circ} \mathrm{C}$ for $15 \mathrm{~s}, 68^{\circ} \mathrm{C}$ for $10 \mathrm{~min}+10 \mathrm{~s}$ per cycle; followed by $68^{\circ} \mathrm{C}$ for $7 \mathrm{~min}$. Amplicons were resolved on $1 \%(\mathrm{w} / \mathrm{v})$ agarose gels at $100 \mathrm{~V}$ for $1 \mathrm{~h}$, purified using the QIAquick ${ }^{\circledR}$ PCR purification Kit (QIAGEN, Hilden, Germany) and quantified using the Quant-i ${ }^{\mathrm{m}}$ PicoGreen ${ }^{\circledR}$ dsDNA assay Kit (Invitrogen) and a Spectramax microplate reader; Molecular Devices Ltd, Wokingham, UK).

\section{Verification of long-PCR amplicon identity and primer region sequences}

Each $(50 \mu \mathrm{L})$ PCR contained either $0.8 \mathrm{pg}$ of amplicon or 20 ng total DNA; 1 x PCR Buffer (Bioline, London, UK), $1.5 \mathrm{mM} \mathrm{MgCl} 2$ (Bioline), $800 \mu \mathrm{M}$ total dNTPs (Bioline), $0.5 \mu \mathrm{M}$ each of primers $16 \mathrm{~S}$ (F and $\mathrm{R}$ ) or COXI (F and R; amplicon 1), Amp1 (F and R; primer region 1) 
Table 4 Primer details

\begin{tabular}{|c|c|c|c|c|c|}
\hline Name & Gene & $\begin{array}{l}\text { Nucleotide } \\
\text { position }\end{array}$ & Sequence $\left(5^{\prime}-3^{\prime}\right)$ & $\begin{array}{l}\text { Amplicon } \\
\text { length } \\
\text { (bp) }\end{array}$ & $\begin{array}{l}\text { Annealing } \\
\text { temp. }\left({ }^{\circ} \mathrm{C}\right)\end{array}$ \\
\hline LongF1 & \multirow[t]{2}{*}{ trnF_atp6/atp6 } & $28-49$ & ACTGAAGATGCTGAGATGAGCC & \multirow[t]{2}{*}{7961} & \multirow[t]{2}{*}{55} \\
\hline LongR2 & & $8012-8033$ & ATGGTCAGTTTCAAGGGTTAGG & & \\
\hline LongF2 & \multirow[t]{2}{*}{ atp6/atp6_trnF } & $8012-8033$ & CCTAACCCTTGAAACTGACCAT & \multirow[t]{2}{*}{9649} & \multirow[t]{2}{*}{55} \\
\hline LongR1 & & $28-49$ & GGCTCATCTCAGCATCTTCAGT & & \\
\hline 16SA-Lmod & \multirow[t]{2}{*}{$r r n L$} & 1943-1962 & CGCCTGTTTACCAAAAACAT & \multirow[t]{2}{*}{580} & \multirow[t]{2}{*}{53} \\
\hline $16 S A-H$ & & $2542-2562$ & CCGGTCTGAACTCAGATCACG & & \\
\hline COX1F & \multirow[t]{2}{*}{$\operatorname{cox} 1$} & $6613-6631$ & GAAACATGAGCAAAAATCC & \multirow[t]{2}{*}{190} & \multirow[t]{2}{*}{53} \\
\hline COX1R & & $6821-6802$ & AATGCTTCTCAGATAATGAA & & \\
\hline ND6F & \multirow[t]{2}{*}{ nad6 } & 13996-14015 & AACATCCCACCTAAATAAAT & \multirow[t]{2}{*}{106} & \multirow[t]{2}{*}{53} \\
\hline ND6R & & 14137-14122 & TAGCTGTTGCTTCAAATCC & & \\
\hline AMP1F & \multirow[t]{2}{*}{ trnF_rrns } & $5-23$ & ACGTAGCTTAAGTAAAGCACAGC & \multirow[t]{2}{*}{294} & \multirow[t]{2}{*}{58} \\
\hline AMP1R & & $322-347$ & ATCAACTTGAGTTTCTCGTATAACC & & \\
\hline $\mathrm{AMP} 2 \mathrm{~F}$ & \multirow[t]{2}{*}{ cox2_trnK_atp6/cox3 } & $7776-7800$ & TCTTCATCAATACTAGAAGCCTCA & \multirow[t]{2}{*}{912} & \multirow[t]{2}{*}{61} \\
\hline AMP2R & & $8712-8731$ & TGTGCTTGGTGTGCCATTA & & \\
\hline
\end{tabular}

The names, gene and nucleotide positions, sequences, expected amplicon lengths and annealing temperatures of PCR primers used to generate the long-amplicons and to verify the specific identity of the long-amplicon and sequences of the primer regions.

or Amp2 (F and R; primer region 2), and 2.5 units BioTaq DNA polymerase (Bioline) and run on the same PCR machine as above at $95^{\circ} \mathrm{C}$ for $5 \mathrm{~min}$; 35 cycles of $94^{\circ} \mathrm{C}$ for $30 \mathrm{sec}$, annealing temperature specific for each primer pair (Table 4) for $30 \mathrm{sec} ; 2^{\circ} \mathrm{C}$ for $30 \mathrm{sec}$, followed by $7 \mathrm{~min}$ at $72^{\circ} \mathrm{C}$. PCR products were resolved on agarose gels, purified and quantified as before then sequenced the ABI BigDye ${ }^{\circledR}$ Terminator cycle sequencing kit v3.1 and the ABI PRISM 3730xl.

\section{Automated sequencing and assembly of the Xenopus mitochondrial genomes using 454}

Amplicon 1 and 2 (15 $\mu \mathrm{g}$ of each) from XB were pooled and then used to construct a fragment library. Fragments were amplified by emulsion PCR, pyrosequenced on a PicoTiterPlateTM and detected via The Genome Sequencer FLX Titanium System ${ }^{\mathrm{TM}}$ (service provided by Beckman Coulter Genomics, UK). Assembly of XB (and $\mathrm{XV}$ described below) used a two-step process, where a tentative consensus assembly was made first, and then original reads were mapped on to that consensus, thereby correcting it. The XB mitochondrial genome was assembled using Roche Newbler v 2.5.3 (Roche) and Mira v 3.2.1 [44]. Initially, 33 preliminary contigs from individual reads exceeding 520 bp were assembled. Contigs were exported as FASTA files and reassembled with Sequencher v. 4.10 (GeneCodes, Inc.), in order to visualise sequencing errors, indels and edit open reading frames, and to make a tentative consensus. Newbler was used to map the original reads back onto this tentative consensus, which made a few corrections to it. Although assembled initially as a linearized genome, Sanger sequences linking the two amplicons provided a fully resolved circular mitochondrial genome.

Amplicon 1 and 2 from XV were pooled $(\sim 0.5 \mathrm{pmol}$ each) with an equimolar mixture of 470 long-PCR amplicons from a range of other species ( $>250$ various metazoans most from different genera and only a few vertebrates; unpublished). A single D-phase library was constructed from the pooled samples and run on a FLX Titanium plate (service provided by Centre for Genomic Research, University of Liverpool). The mitochondrial genomes, among them XV, were assembled automatically using Mira v 3.2.1.17, with the "accurate" option [44]. In order to avoid chimeric assemblies from the multiplexed pool of amplicons, only reads $>=150 \mathrm{bp}$ were chosen for the assembly. Putative XV contigs were identified by BLASTN, where the top hit was to a known Xenopus $\mathrm{mt}$ sequence. Those contigs were aligned to the $X$. laevis mitochondrial genome (HM991335) using BLASTn to make a tentative consensus of $17735 \mathrm{bp}$. All 9864 of the 454 reads that went into those contigs were extracted from as a separate sff file. Those reads were then mapped against the tentative consensus to make the final sequence. Both Mira and Newbler were trialled to do the mapping, but in this case Mira was used because Newbler introduced a frameshift in the atp 6 gene but Mira did not. The final mapping was $17731 \mathrm{bp}$ long, using 6627 of the 9864 reads were used to make the consensus. The sequences were confirmed using Sanger tags, which had exact matches except for a few alignment gaps near the ends of the tags. 


\section{Annotation and characterisation of tRNAs, rRNAs, D-loop and protein coding regions}

Mitochondrial genomes of Хепориs were annotated using MacVector v. 12.0 (MacVector Inc.). Open reading frames were found employing the 'vertebrate mitochondrial code' and inferred translated proteins were confirmed by means of BLAST analysis. Initiation and termination codons were verified through comparison with published mtDNAs of Xenopus and other amphibians. The positions of all transfer RNA genes were identified using tRNAscan SE 1.21 [45] or ARWEN [46]. The rRNA genes and control region were identified by BLASTn analysis and comparisons with respective sequences within the XL and ST mitochondrial genomes.

\section{Phylogenetic, nucleotide variation and non-synonymous/ synonymous substitution rate analysis of protein coding regions}

Two early divergent members of the Pipidea: Pipa carvalhoi and Hymenochirus boettgeri, were selected as suitable outgroups. For protein coding genes only, the Xenopus and outgroup nucleotide sequences were aligned by eye, with reference to gene boundaries and were held in frame. All positions were unambiguously alignable. The alignment was translated into amino acids yielding 3,782 positions; none were excluded from the analysis as all could be aligned unambiguously. Phylogenetic trees were constructed using Bayesian inference (BI) with MrBayes, version 3.1.2 [47], employing the mixed amino acid model. Two runs, with four chains each (temp $=0.2$ ), were run for 5,000,000 generations and sampled every 1000 generations; 500,000 generations were discarded as burn-in.

\section{Sliding window analysis}

Sliding window analysis was performed on the aligned, complete mitochondrial genome nucleotide sequences of the four Xenopus species. Analyses were conducted on the full alignment, and from this also all combinations of pairwise comparisons between Xenopus species. Protein-coding genes were aligned in frame, as per the alignment conducted for the phylogenetic analysis. Intergenic regions, tRNA and rRNA genes were aligned by eye; although this was achieved with little ambiguity the region covering the D-loop could not be unambiguously aligned as a result of significant length and sequence differences. A sliding window of $300 \mathrm{bp}$ and steps of $10 \mathrm{bp}$ was used to estimate nucleotide divergence $\mathrm{K}(\mathrm{JC})$ between all species and between all pairs of species over the entire alignment using DnaSP v.5 [35]. Nucleotide divergence, for the entire and pairwise alignments, was plotted against midpoint positions of each window, and gene boundaries indicated.
Nonsynonymous $(\mathrm{dN})$ and synonymous $(\mathrm{dS})$ substitution between the Xenopus protein-coding sequences was estimated with KaKs Calculator using a modified version of the Yang-Nielsen algorithm, which is based on the Tamura-Nei Model that considers the difference among rates of transitional and transversional substitutions as well as factors in codon frequency bias [48]. $\mathrm{dN}$ and $\mathrm{dS}$ (or their ratio $\omega=\mathrm{dN} / \mathrm{dS}$ ) are used to categories genes into three groups, those undergoing: negative (purifying) selection $(\omega<1)$, positive (adaptive) selection $(\omega>1)$, and neutral selection $(\omega=1)$.

\section{Expressed sequence tag database mining of protein coding sequences}

Each ST protein coding sequence was inputted into Xenbase [43], which contains ST expressed sequence tags (ESTs), from different developmental stages (unfertilised egg, cleavage, blastula, gastrula, neurula and tailbud), to look for clones containing mtDNA genes. Only matches with $\geq 90 \%$ similarity with the inputted sequence were reported.

\section{Competing interests}

The authors declare that they have no competing interests.

\section{Authors' contributions}

$\mathrm{RL}$ conceived and designed the Xenopus borealis mitogenome sequencing, carried out the egg collections, DNA extractions, long-PCRs, short amplicon verifications and EST analyses. DTJL conceived and designed the Xenopus victorianus mitogenome sequencing, annotated both mitogenomes, and carried out phylogenetic, sliding window, and dN/dS analyses. RE and DTJL led on drafting the manuscript. PF assembled both Xenopus mitogenomes and helped draft the manuscript. MG oversaw the animal experiments and helped draft the manuscript. All authors read and approved the final manuscript.

\section{Acknowledgements}

$\mathrm{RL}$ is grateful for funding from the Leverhulme Trust (ECF/2009/0123). DTJL and PF are grateful for funding from BBSRC (BB/H023534). We are grateful to the European Xenopus Resource Centre (EXRC) for contributing Xenopus eggs and facilities as part of their "Research Hotel" function.

\section{Author details}

${ }^{1}$ Institute of Biomedical and Biomolecular Sciences, University of Portsmouth, Portsmouth PO1 2DT, UK. ²Department of Zoology, Natural History Museum, Cromwell Road, London SW7 5BD, UK. ${ }^{3}$ Institute of Zoology, Zoological Society of London, Regent's Park, London, NW1 4RY, UK.

Received: 12 June 2012 Accepted: 13 September 2012 Published: 19 September 2012

\section{References}

1. Wallace DC: Mitochondrial diseases in man and mouse. Science 1999, 283(5407):1482-1488.

2. Avise JC: Molecular Marker, Natural History and Evolution. 2nd edition. 2004.

3. Alacs EA, Georges A, FitzSimmons NN, Robertson J: DNA detective: a review of molecular approaches to wildlife forensics. Forensic Sci Med Pathol 2009, 6(3):180-194.

4. Jarman PG, Fentress SL, Katz DE: Mitochondrial DNA validation in a state laboratory. J Forensic Sci 2009, 54(1):95-102.

5. Gibb GC, Kardailsky O, Kimball RT, Braun EL, Penny D: Mitochondrial genomes and avian phylogeny: complex characters and resolvability without explosive radiations. Mol Biol Evol 2007, 24(1):269-280.

6. Phillips MJ, Penny D: The root of the mammalian tree inferred from whole mitochondrial genomes. Mol Phylogenet Evol 2003, 28(2):171-185. 
7. Miya M, Takeshima H, Endo H, Ishiguro NB, Inoue JG, Mukai T, Satoh TP, Yamaguchi M, Kawaguchi A, Mabuchi K, et al: Major patterns of higher teleostean phylogenies: a new perspective based on 100 complete mitochondrial DNA sequences. Mol Phylogenet Evol 2003, 26(1):121-138.

8. Alam MS, Kurabayashi A, Hayashi Y, Sano N, Khan MR, Fujii T, Sumida M: Complete mitochondrial genomes and novel gene rearrangements in two dicroglossid frogs, Hoplobatrachus tigerinus and Euphlyctis hexadactylus, from Bangladesh. Genes Genet Syst 2010, 85(3):219-232.

9. Bi K, Bogart JP: Time and time again: unisexual salamanders (genus Ambystoma) are the oldest unisexual vertebrates. BMC Evol Biol 2010, $10: 238$.

10. San Mauro D, Gower DJ, Zardoya R, Wilkinson M: A hotspot of gene order rearrangement by tandem duplication and random loss in the vertebrate mitochondrial genome. Mol Biol Evol 2006, 23(1):227-234

11. Zhang $P$, Chen YQ, Zhou H, Liu YF, Wang XL, Papenfuss TJ, Wake DB, Qu $\mathrm{LH}$ : Phylogeny, evolution, and biogeography of Asiatic Salamanders (Hynobiidae). Proc Natl Acad Sci U S A 2006, 103(19):7360-7365.

12. The IUCN Red List of Threatened Species. Version 2011.2. 2011. http://www iucnredlist.org/(Downloaded 29 May 2012).

13. Kilpatrick AM, Briggs CJ, Daszak P: The ecology and impact of chytridiomycosis: an emerging disease of amphibians. Trends Ecol Evol 2010, 25(2):109-118.

14. Maya-Soriano MJ, Holt WV, Lloyd RE: Biobanked Amphibian Samples Confirmed To Species Level Using 16S rRNA DNA Barcodes. Biopreservation Biobanking 2012, 10(1):22-28

15. Pyron RA, Wiens JJ: A large-scale phylogeny of Amphibia including over 2800 species, and a revised classification of extant frogs, salamanders, and caecilians. Mol Phylogenet Evol 2011, 61(2):543-583.

16. Meier $R$, Zhang G, Ali F: The use of mean instead of smallest interspecific distances exaggerates the size of the "barcoding gap" and leads to misidentification. Syst Biol 2008, 57(5):809-813

17. Boore JL: The use of genome-level characters for phylogenetic reconstruction. Trends Ecol Evol 2006, 21(8):439-446.

18. Zarowiecki MZ, Huyse T, Littlewood DT: Making the most of mitochondrial genomes-markers for phylogeny, molecular ecology and barcodes in Schistosoma (Platyhelminthes: Digenea). Int J Parasitol 2007, 37(12):1401-1418.

19. Sumida M, Kanamori $Y$, Kaneda $H$, Kato $Y$, Nishioka M, Hasegawa M, Yonekawa $\mathrm{H}$ : Complete nucleotide sequence and gene rearrangement of the mitochondrial genome of the Japanese pond frog Rana nigromaculata. Genes Genet Syst 2001, 76(5):311-325

20. D'Errico I, Gadaleta G, Saccone C: Pseudogenes in metazoa: origin and features. Brief Funct Genomic Proteomic 2004, 3(2):157-167.

21. Wolff JN, Shearman DC, Brooks RC, Ballard JW: Selective enrichment and sequencing of whole mitochondrial genomes in the presence of nuclear encoded mitochondrial pseudogenes (numts). PLOS One 2012, 7(5):e37142.

22. Jex AR, Hall RS, Littlewood DT, Gasser RB: An integrated pipeline for nextgeneration sequencing and annotation of mitochondrial genomes. Nucleic Acids Res 2010, 38(2):522-533.

23. Timmermans MJ, Dodsworth $S$, Culverwell CL, Bocak L, Ahrens D, Littlewood DT, Pons J, Vogler AP: Why barcode? High-throughput multiplex sequencing of mitochondrial genomes for molecular systematics. Nucleic Acids Res 2010, 38(21):e197.

24. Harland RM, Grainger RM: Xenopus research: metamorphosed by genetics and genomics. Trends Genet 2011, 27(12):507-515

25. Roe BA, Ma DP, Wilson RK, Wong JF: The complete nucleotide sequence of the Xenopus laevis mitochondrial genome. J Biol Chem 1985, 260(17):9759-9774

26. Perna NT, Kocher TD: Patterns of nucleotide composition at fourfold degenerate sites of animal mitochondrial genomes. J Mol Evol 1995, 41(3):353-358

27. Castellana S, Vicario S, Saccone C: Evolutionary patterns of the mitochondrial genome in Metazoa: exploring the role of mutation and selection in mitochondrial protein coding genes. Genome Biol Evol 2011, 3:1067-1079.

28. Reyes A, Gissi C, Pesole G, Saccone C: Asymmetrical directional mutation pressure in the mitochondrial genome of mammals. Mol Biol Evol 1998, 15(8):957-966

29. Sano N, Kurabayashi A, Fujii T, Yonekawa H, Sumida M: Complete nucleotide sequence and gene rearrangement of the mitochondrial genome of the bell-ring frog, Buergeria buergeri (family Rhacophoridae). Genes Genet Syst 2004, 79(3):151-163.

30. Ojala D, Merkel C, Gelfand R, Attardi G: The tRNA genes punctuate the reading of genetic information in human mitochondrial DNA. Cell 1980, 22(2 Pt 2):393-403

31. Irisarri I, Vences M, San Mauro D, Glaw F, Zardoya R: Reversal to air-driven sound production revealed by a molecular phylogeny of tongueless frogs, family Pipidae. BMC Evol Biol 2011, 11:114

32. Evans BJ, Kelley DB, Tinsley RC, Melnick DJ, Cannatella DC: A mitochondrial DNA phylogeny of African clawed frogs: phylogeography and implications for polyploid evolution. Mol Phylogenet Evol 2004, 33(1):197-213.

33. Frost DR: Amphibian Species of the World. an Online Reference. Version 5.5 Electronic Database accessible at http://research.amnh.org/vz/herpetology/ amphibia/. 2011(Downloaded 31 January, 2011).

34. Evans BJ, Kelley DB, Melnick DJ, Cannatella DC: Evolution of RAG-1 in polyploid clawed frogs. Mol Biol Evol 2005, 22(5):1193-1207.

35. Rozas J, Sanchez-DelBarrio JC, Messeguer X, Rozas R: DnaSP, DNA polymorphism analyses by the coalescent and other methods. Bioinformatics 2003, 19(18):2496-2497.

36. Vences $M$, Thomas M, Bonett RM, Vieites DR: Deciphering amphibian diversity through DNA barcoding: chances and challenges. Philos Trans $R$ Soc Lond B Biol Sci 2005, 360(1462):1859-1868.

37. Folmer O, Black M, Hoeh W, Lutz R, Vrijenhoek R: DNA primers for amplification of mitochondrial cytochrome c oxidase subunit I from diverse metazoan invertebrates. Mol Mar Biol Biotechnol 1994, 3(5):294-299.

38. Xia Y, Gu HF, Peng R, Chen Q, Zheng YC, Murphy RW, Zeng XM: COI is better than 16S rRNA for DNA barcoding Asiatic salamanders (Amphibia: Caudata: Hynobiidae). Mol Ecol Resour 2011, 12(1):48-56.

39. Rawlings TA, Collins TM, Bieler R: Changing identities: tRNA duplication and remolding within animal mitochondrial genomes. Proc Natl Acad Sci U S A 2003, 100(26):15700-15705.

40. Tsukihara T, Aoyama H, Yamashita E, Tomizaki T, Yamaguchi H, ShinzawaItoh K, Nakashima R, Yaono R, Yoshikawa S: The whole structure of the 13-subunit oxidized cytochrome c oxidase at 2.8 A. Science 1996, 272(5265):1136-1144.

41. Soto IC, Fontanesi F, Liu J, Barrientos A: Biogenesis and assembly of eukaryotic cytochrome c oxidase catalytic core. Biochim Biophys Acta 2012, 1817(6):883-897.

42. Efremov RG, Sazanov LA: Respiratory complex I: 'steam engine' of the cell? Curr Opin Struct Biol 2011, 21(4):532-540.

43. Bowes JB, Snyder KA, Segerdell E, Jarabek CJ, Azam K, Zorn AM, Vize PD: Xenbase: gene expression and improved integration. Nucleic Acids Res 2009, 38(Database issue):D607-D612.

44. Chevreux B: MIRA: An Automated Genome and EST Assembler. Germany: Heidelberg University; 2006.

45. Lowe TM, Eddy SR: tRNAscan-SE: a program for improved detection of transfer RNA genes in genomic sequence. Nucleic Acids Res 1997, 25(5):955-964.

46. Laslett $D$, Canback B: ARWEN: a program to detect tRNA genes in metazoan mitochondrial nucleotide sequences. Bioinformatics 2008, 24(2):172-175

47. Huelsenbeck JP, Ronquist F: MRBAYES: Bayesian inference of phylogenetic trees. Bioinformatics 2001, 17(8):754-755.

48. Zhang Z, Li J, Yu J: Computing Ka and Ks with a consideration of unequal transitional substitutions. BMC Evol Biol 2006, 6:44.

doi:10.1186/1471-2164-13-496

Cite this article as: Lloyd et al:: Next generation sequencing and comparative analyses of Xenopus mitogenomes. BMC Genomics 2012 13:496. 